\title{
Polyaniline/Nanomaterial Composites for the Removal of Heavy Metals by Adsorption: A Review
}

\author{
Hind Hajjaoui, Amal Soufi, Wafaa Boumya, Mohamed Abdennouri and Noureddine Barka *D
}

MRI Laboratory, Research Group in Environmental Sciences and Applied Materials (SEMA), Sultan Moulay Slimane University of Beni Mellal, FP Khouribga, Khouribga 25000, Morocco; hind.hajjaoui@usms.ac.ma (H.H.); amal.soufi@usms.ac.ma (A.S.); wafboumya@gmail.com (W.B.); m.abdennouri@usms.ma (M.A.)

* Correspondence: barkanoureddine@yahoo.fr; Tel.: +212-661666622

Citation: Hajjaoui, H.; Soufi, A.; Boumya, W.; Abdennouri, M.; Barka, N. Polyaniline/Nanomaterial Composites for the Removal of Heavy Metals by Adsorption: A Review. J. Compos. Sci. 2021, 5, 233. https://doi.org/10.3390/jcs5090233

Academic Editor: Francesco Tornabene

Received: 7 August 2021

Accepted: 31 August 2021

Published: 3 September 2021

Publisher's Note: MDPI stays neutral with regard to jurisdictional claims in published maps and institutional affiliations.

Copyright: (C) 2021 by the authors. Licensee MDPI, Basel, Switzerland. This article is an open access article distributed under the terms and conditions of the Creative Commons Attribution (CC BY) license (https:// creativecommons.org/licenses/by/ $4.0 /)$.

\begin{abstract}
Heavy metals represent one of the most important kinds of pollutants, causing serious threats to the ecological balance. Thus, their removal from aqueous solution is a major environmental concern worldwide. The process of adsorption — being very simple, economical, and effective-is widely applied for the decontamination of wastewaters from heavy metals. In this process, the adsorbent is the key factor affecting the performance; for this reason, significant efforts have been made to develop highly efficient and selective adsorbents with outstanding properties. This paper presents a detailed overview of the research on different methods of synthesis of nanocomposite materials based on the polymer polyaniline combined with nanomaterials, along with the influence of the synthesis method on their size, morphology, and properties. In addition, the study evaluates the adsorption efficiency of various developed nanocomposites for the adsorption of heavy metals from aqueous solution. From an economical and environmental point of view, the regeneration studies of the nanocomposites are also reported.
\end{abstract}

Keywords: nanocomposites; conductive polymer; heavy metals removal; remediation

\section{Introduction}

Accelerated urbanization and industrialization have led to a steady deterioration in the quality of available water, which has caused an imbalance in our ecosystem. Surface water and groundwater are contaminated by various organic and inorganic pollutants - among them, heavy metals. Despite the fact that some metals are essential, at very low concentrations, to maintain various biochemical and physiological functions in living organisms, they become noxious when they exceed certain threshold concentrations. Others are considered to be highly toxic even at trace concentrations. The sources of heavy metals in water are either natural or anthropogenic. Natural sources include soil erosion, volcanic activity, and weathering of rocks and minerals. On the other hand, anthropogenic sources are related to a variety of industries, i.e., mining, metal corrosion inhibition, electroplating, batteries, tanneries, plastics, fertilizers, microelectronics, petrochemicals, and metallurgy. Exposure to heavy metals has proven to be a serious threat. There are several related health risks, including neurodegenerative diseases (Alzheimer's and Parkinson's diseases), oxidative stress and subsequent tissue damage [1,2], cardiovascular diseases, liver cancer, kidney damage, and renal cancer. Autism may also be associated with Hg toxicity [3], along with malfunctioning of the immune system, birth defects, and behavioral changes in children [4].

It has been estimated that one-third of world's population may be affected by the lack of safe drinking water [5]. In view of this increasing demand for water and its decreasing availability, a major environmental issue facing every country today is the reuse of polluted water and the removal of heavy metals before its disposal for safe discharge in the environment. Intensive research on the effective treatment of heavy metals has resulted in several technologies, including ion exchange, precipitation, electrocoagulation, 
and membrane separation. In spite of being efficient, these methods suffer from some drawbacks, such as high capital demands, high energy requirements and operational costs, being time-consuming, low removal efficiency, and the disposal problem of residual metal sludge [6]. Consequently, it remains challenging to develop an efficient, economical, and sustainable technology.

According to the Scopus database, 25,277 articles have been published from 2010 to 2020 using different techniques for the removal of heavy metals. Among the used techniques, the adsorption process represents $65 \%$ of the total published studies, as illustrated in Figure 1. To date, various materials including raw and modified bioadsorbents $[7,8]$, polymers [9], nanocomposites [10], hybrids [11], silica-based materials [12], and inorganic [13] and carbon-based materials [14] have been studied for the recovery of heavy metals.

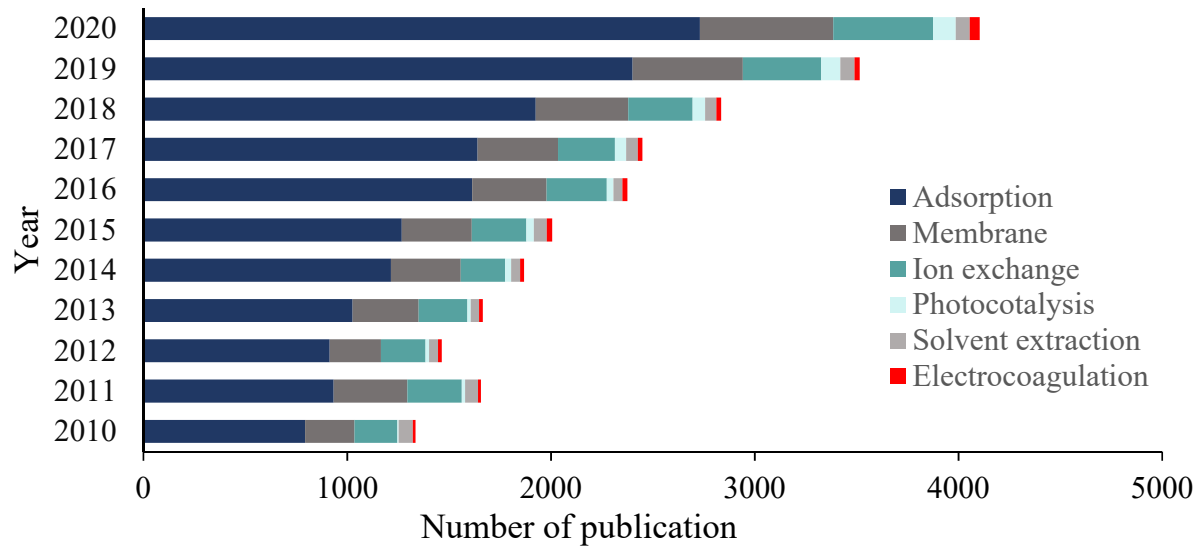

Figure 1. Publications on the removal of heavy metals via different techniques from 2010 to 2020, based on the Scopus database.

In the past decade, the development of nanotechnology has shown remarkable potential for the remediation of environmental problems. Nanomaterials have been used as efficient adsorbents for the removal of heavy metals, owing to their distinctive physicochemical properties - in particular, their high specific-surface-area-to-volume ratio, high capacity, high selectivity, and the availability of a large number of active groups for binding heavy metals [15]. However, these nanomaterials have encountered various difficulties, such as high costs, nanotoxicity, and poor efficiency of separation and recycling after use, and may also lead to novel types of pollutant that have negative effects on living organisms and ecosystems [16].

An effective approach to overcoming some of these limitations is the incorporation of nanomaterials into another matrix, leading to nanocomposite materials that are multiphase solids where one of the phases has one, two, or three dimensions of less than $100 \mathrm{~nm}$ [17]. They are classified into three major types based on the matrix material: ceramic matrix nanocomposites, metal matrix nanocomposites, and polymer matrix nanocomposites [18]. Polymer nanocomposites-the most preferred-are synthesized by the introduction of nanostructured materials into a polymer matrix in order to integrate their properties into a single material, resulting in a promising material with potential properties such as easy preparation, cost-effectiveness, environmental stability, effective binding sites along the walls of the polymers with large surface area, and pore volume [19]. Among all polymers, polyaniline is the most studied, as demonstrated in Figure 2, due to the monomer's low cost, chemical and environmental stability, ease of synthesis, high electrical conductivity, and biocompatibility; furthermore, it possesses a large number of amine and imine functional groups that interact with some metal ions due to the strong affinity of nitrogen atoms $[20,21]$. For this reason, polyaniline has been chosen as a platform to build innovative nanocomposite adsorbents by mixing it with other nanomaterials that exhibit better adsorption capacities, chemical and thermal stability, good regeneration ability, and selectivity toward heavy metals using simple synthesis methods. 


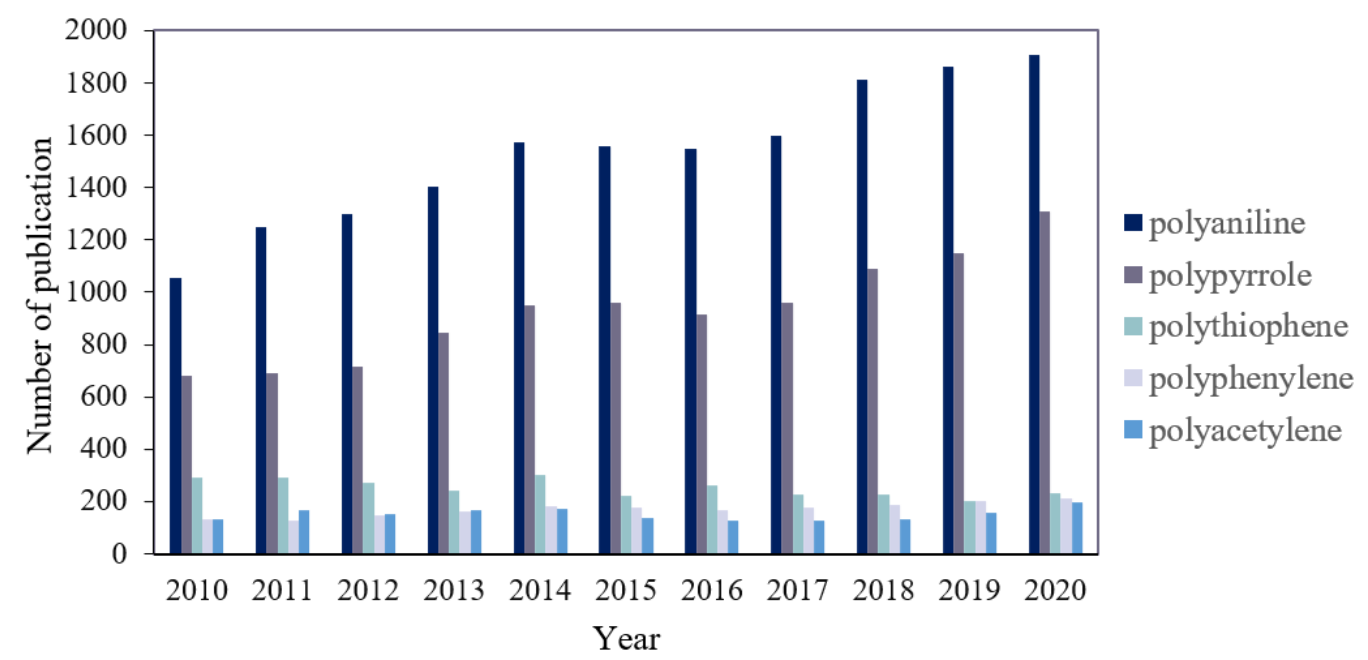

Figure 2. Evolution of the number of published papers between 2010 and 2020 with the keywords: "polyaniline", "polypyrrole", "polythiophene" "polyphenylene", and "polyacetylene", based on the Scopus database.

This review paper outlines approaches to the removal of heavy metals from aqueous solution using polyaniline nanocomposites to date, reporting the synthesis methods and structural properties of the prepared nanocomposites. We focus on the adsorption efficiency and regeneration capacity of the developed materials to provide a background for future research. This article is structured in such a way that information on polyaniline and different methods used for its synthesis are described. Moreover, the commonly used polyaniline nanocomposites for the adsorption of metal ions and regeneration studies are also reported.

\section{Polyaniline Polymer}

Polyaniline, commonly abbreviated as PANI or Pani-also known as aniline blackwas discovered for the first time by Ferdinand Runge in 1834 from the initial oxidation of aniline. Later, in 1862, Henry Letherby achieved its first electrochemical polymerization. Since then, it has been applied in a variety of colored materials and dyes. Recently, PANI has gained much attention of the scientific community due to the rediscovery of its conductive properties in the 1980s. Its structure consists of a succession of aromatic rings of the benzene diamine and/or quinone di-imine types, bridged by a nitrogen heteroatom. PANI has three oxidation states that are represented in Figure 3: fully reduced leucoemeraldine base (LB), fully oxidized pernigraniline base (PB), and half-oxidized emeraldine base (EB) — which is converted to emeraldine salt via protonation with organic and inorganic acids [22].

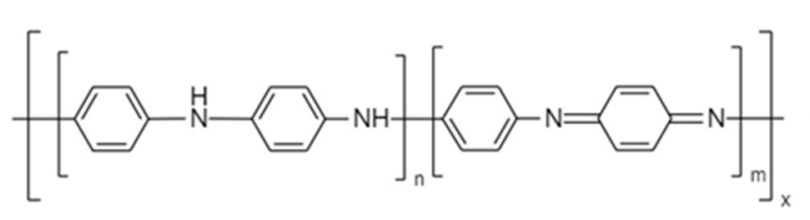

Basic structure of Polyaniline

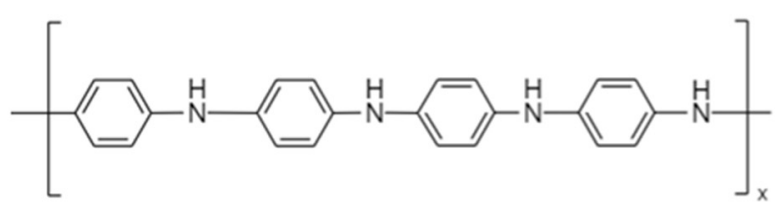

Leucomeraldine Base<smiles>CC(C)(C)N=C1C=CC(=NC2C=CC(=NC3C=CC(=Nc4ccc(C(C)(C)C)cc4)C=C3)C=C2)C=C1</smiles>

Pernigraniline Base

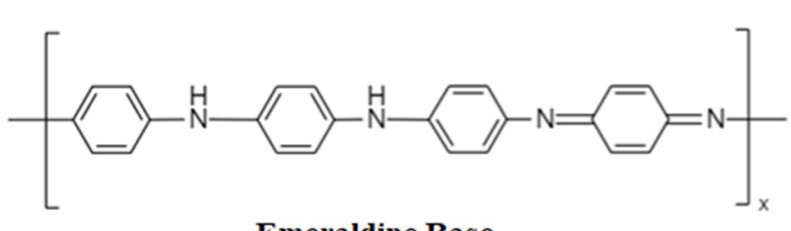

Emeraldine Base

Figure 3. Different configurations of PANI structures. 
PANI can be synthesized using both chemical and electrochemical oxidative polymerization in acidic media. The most widely used initiators or oxidants for the chemical polymerization of aniline are ammonium persulfate (APS) and potassium persulfate (KPS), which give higher conversion and yield. The variation in experimental synthesis conditions leads to a large variety of macromolecular structures of PANI, as illustrated in Figure 4. The formation of these morphologies is related to many parameters, including the type of acid and associated anionic dopant, the temperature of the synthesis, the molar ratio of aniline/oxidant, and the presence of surfactant. Li et al. [23] prepared PANI in the presence of three different inorganic acids $-\mathrm{HCl}, \mathrm{H}_{2} \mathrm{SO}_{4}$, and $\mathrm{HNO}_{3}$ - and a combination of $\mathrm{FeCl}_{2}$ /chloroform as an oxidant. PANI- $\mathrm{HCl}$ displayed a nanofibrous structure with particle diameter of $30-50 \mathrm{~nm}, \mathrm{H}_{2} \mathrm{SO}_{4}$ produced a nanogranular structure with a particle diameter of $400 \mathrm{~nm}$, and $\mathrm{HNO}_{3}$ yielded a hollow, ball-like structure with a particle diameter of 1-1.4 um. On the other hand, Shen et al. [24] synthesized PANI in the presence of sulfonic acids, and found that the prepared PANI exhibited a high degree of protonation, along with high conjugation, length, crystallinity, and electrical properties as compared to PANI prepared in common $\mathrm{HCl}$ medium. Recently, green synthesis of PANI was reported by Rahman et al. [25], with a fibrous porous nanostructure network using sodium phytate as a dopant; the polymer exhibited a specific surface area of $230 \mathrm{~m}^{2} / \mathrm{g}$. In another study, PANI with an elliptical morphology was prepared using iron chlorophyll-a as biomimic catalyst [26].

Although PANI exhibits high efficiency in the removal of heavy metals, the particles easily aggregate during the chemical synthesis, which limits its adsorption capacity and practical application. Moreover, recycling the PANI powders after treatment remains a challenge due to its small particle size [27]. Many studies have been carried out in order to enhance the removal efficiency of PANI, and to reduce the toxicity and enhance the stability of nanomaterials; as a result, different polyaniline/nanomaterial nanocomposites have been reported for the removal of heavy metals. PANI in combination with nanomaterials displays not only improved mechanical features, but also enhanced performance.
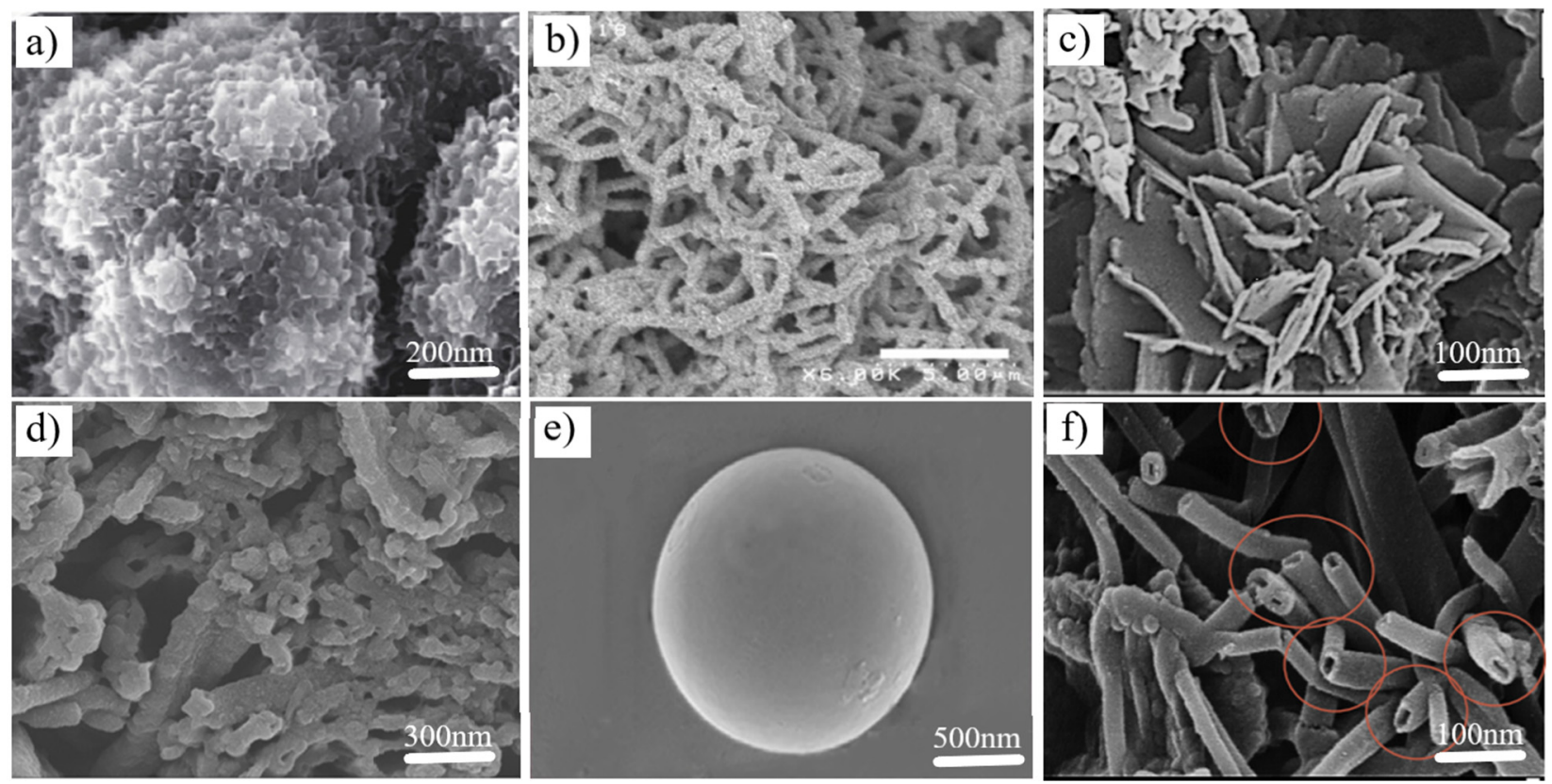

Figure 4. SEM images of different structures of PANI polymer: (a) 3D hierarchical PANI [28], (b) nanowire [29], (c) nanoflowers [30], (d) nanorods [31], (e) microspheres [32], (f) nanotubes [33]. 


\section{Polyaniline Nanocomposites Synthesis}

Synthetic strategies for the preparation of nanocomposites are of great importance, as they influence the resulting product in terms of its morphology and properties. In the available literature reviewed for this study, PANI/nanomaterial composites have generally been synthesized based on three paths, as represented in Figure 5:

(a) In situ polymerization of aniline monomer on the surface of the nanomaterials;

(b) One-step redox reactions where the polymerization and the formation of the nanomaterial occur simultaneously;

(c) Physical mixing of the pre-synthesized PANI and nanomaterials.
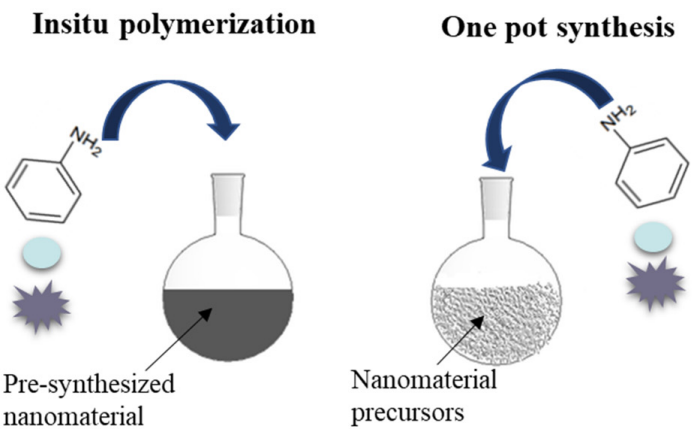

Physical mixing

Figure 5. Schematic illustration of different methods for the synthesis of PANI nanocomposites.

In this section, different synthesis approaches to PANI/NM nanocomposites are reviewed, and relationships between the synthesis strategy, structural formation, physical and mechanical properties, and characteristics are reported and discussed.

\subsection{In Situ Polymerization}

In situ polymerization is the most widely used method for the preparation of PANI nanocomposites. The polymerization of aniline occurs on the surface of pre-synthesized NMs in acidic media in the presence of an oxidant. Several factors affect the reaction rate, the nanocomposite size, and its properties, including the molar ratio of aniline to oxidant, the weight ratio of aniline to nanomaterial, the nature of the dopant, and temperature. This process includes microemulsion polymerization and inverse microemulsion polymerization.

\subsubsection{Microemulsion Polymerization}

One of the suitable techniques for the preparation of PANI nanocomposites is the microemulsion method. Usually, a typical microemulsion system contains water, oil, and a surfactant, and also often a co-surfactant to stabilize the system, which is commonly a shortchain alcohol. It is well known that microemulsion polymerization is an effective method in producing polymers at a nanometric scale $(5-100 \mathrm{~nm})$. In this procedure, nanoparticles surrounded by surfactant molecules provide micelles that can act as a surface for the aniline monomer. The system is stabilized by a surfactant, and the polymerization reaction is carried out. The mechanism of formation is as follows: The surfactant self-assembles over the surface of the nanomaterial to form a micelle structure. Afterwards, acid-base interaction occurs between the organic group of the surfactant and the amine group in the aniline. The oxidant is added dropwise to the solution in order to start the polymerization, which only takes place on the surface of the nanoparticles.

Sun et al. [34] reported the synthesis of an $\mathrm{Fe}_{3} \mathrm{O}_{4} / \mathrm{PANI}$ nanocomposite via the microemulsion polymerization of $\mathrm{Fe}_{3} \mathrm{O}_{4}$ and aniline monomer using SDBS as surfactant and n-pentanol as a co-surfactant. First, a microemulsion mixture was prepared by dispersing SDBS and n-pentanol in $\mathrm{HCl}$. Second, $\mathrm{Fe}_{3} \mathrm{O}_{4} \mathrm{NPs}$ modified with oleic acid (in order to improve their dispersity in hexane) were dispersed in n-hexane, and aniline monomers were added to the above microemulsion system. Finally, APS was added as an oxidant in 
order to start the polymerization. In this microemulsion system, the oleic-acid-modified $\mathrm{Fe}_{3} \mathrm{O}_{4}$ in n-hexane was enveloped by SDBS micelles, and aniline monomers could be attracted around the micelles to polymerize as the PANI shell. The $\mathrm{Fe}_{3} \mathrm{O}_{4} / \mathrm{PANI}$ obtained via this method had a monodispersed core-shell structure with a diameter of $\sim 20 \mathrm{~nm}$ and superparamagnetic properties. In another work [35], a nanocable core-shell structure of MWCNT/PANI was prepared via the addition of MWCNT to a microemulsion system of $\mathrm{HCl}$, hexane, DBAS as a surfactant, butanol as a co-surfactant, and aniline. The reaction initiator (APS) was added slowly to initiate the polymerization of the aniline monomer. Finally, the reaction mixture was filtered and rinsed with methanol and water repeatedly.

\subsubsection{Inverse Emulsion Polymerization}

The inverse emulsion polymerization process involves the formation of an aqueous solution of the monomer, which is emulsified in a nonpolar organic solvent such as chloroform, isooctane, toluene, xylene, or hexane-or in a mixture of them-and the polymerization is initiated with an initiator. The reaction is carried out in a heterogeneous system, which has several distinct advantages, as in the emulsion polymerization. The physical state of the emulsion system makes it easier to control the process. Karim et al. [36] synthesized a nanosized $\mathrm{PANI} / \mathrm{TiO}_{2}$ nanocomposite with an average diameter of 50-200 nm, as follows: $\mathrm{CTAB}$ as an emulsifier was dispersed in water and chloroform, followed by the addition of $\mathrm{TiO}_{2} \mathrm{NPs}$ and aniline dissolved in $\mathrm{HCl}$. In order to start the polymerization, APS dissolved in distilled water was added dropwise as an oxidant. Finally, the mixture was stirred for $24 \mathrm{~h}$ and a greenish emulsion was obtained. The organic phase was separated and washed repeatedly with water, and then acetone was added in order to precipitate the nanocomposites. In another work [37], a PANI/GO nanocomposite was prepared using dynamic interfacial inverse emulsion polymerization. An aniline monomer was added to DBSA dissolved in chloroform followed, by the addition of a graphene sheet. The mixture was ultrasonicated, and then APS dissolved in distilled water was added. The PANI/graphene dispersion was precipitated in ethyl alcohol, followed by gravitational filtration.

\subsection{One-Pot Synthesis Method}

In this method, successive chemical reactions are carried out in the same reactor. There are two approaches to the synthesis of nanocomposites using this method: the synthesis of the nanomaterial followed by the polymerization of aniline on its surface; or the synthesis of the PANI polymer followed by the addition of metal salts. This method is widely used for the synthesis of PANI/metal oxide NP nanocomposites. In this context, Wang et al. [38] prepared $\mathrm{PANI} / \mathrm{TiO}_{2}$ through one-pot synthesis. $\mathrm{TiO}_{2}$ was hydrolyzed from titanium isopropoxide and citric acid; after $1 \mathrm{~h}$ of reaction, aniline monomer was added, and then APS added dropwise as an oxidant in order to start the polymerization. The morphological studies revealed that the nanocomposite displayed a core-shell structure with PANI partially covering $\mathrm{TiO}_{2}$ NPs. Pina et al. [39] prepared $\mathrm{Fe}_{3} \mathrm{O}_{4} / \mathrm{PANI}$ via one-pot synthesis using $\mathrm{N}$-(4-aminophenyl) aniline and molecular oxygen or $\mathrm{H}_{2} \mathrm{O}_{2}$ as green, ecofriendly oxidizing agents in the presence of $\mathrm{Fe}_{3} \mathrm{O}_{4} \mathrm{NPs}$ in powder and ferrofluid forms. The obtained nanocomposites exhibited superparamagnetic properties at room temperature. Ferrofluid-type $\mathrm{Fe}_{3} \mathrm{O}_{4}$ NPs displayed nanorod morphology, with diameters between 30 and $110 \mathrm{~nm}$. However, $\mathrm{Fe}_{3} \mathrm{O}_{4} \mathrm{NP}$ powder exhibited more irregular structures.

\subsection{Physical Mixing}

The physical mixing is the most classical and simple method to prepare PANI nanocomposites, because it involves simple mixing of materials that can be performed in solution or via a solid-state reaction. Zong et al. [40] synthesized a magnetic GO/PANI nanocomposite for the adsorption of $\mathrm{Cd}(\mathrm{II})$ using induced plasma in a custom-built reactor where the GO surface was first activated under the experimental conditions of voltage of $900 \mathrm{~V}$, gas pressure of $10 \mathrm{~Pa}$, and power of $100 \mathrm{~W}$. Afterwards, a solution of PANI particles was rapidly poured, and the reaction occurred at a temperature of $60^{\circ} \mathrm{C}$ for $48 \mathrm{~h}$ under continuous stirring and 
$\mathrm{N}_{2}$ protection. In another study, a polyaniline montmorillonite nanocomposite was prepared using a mechanochemical intercalation method [41]. Sodium montmorillonite and anilinium chloride were mixed in a mortar, followed by the addition of APS.

\section{Polyaniline/Nanomaterial Composites for Adsorption of Heavy Metals}

Nanocomposites based on PANI and nanomaterials have attracted much attention in the past decade for the adsorption of heavy metals. These nanocomposites display enhanced adsorption performance as compared to individual materials. These PANI nanocomposites can be divided into the following groups: PANI/metal oxides, PANI/ carbonaceous nanomaterials, PANI/silica, and PANI/nanoclays. This review focuses on the physicochemical properties of the prepared materials, their adsorption capacity, and their mechanism of adsorption of heavy metals. Based on the reviewed literature, $\mathrm{Fe}_{3} \mathrm{O}_{4} / \mathrm{PANI}$ magnetic nanocomposites and multifunctional magnetic nanocomposites are the most used materials for the adsorption of metal ions (Figure 6).

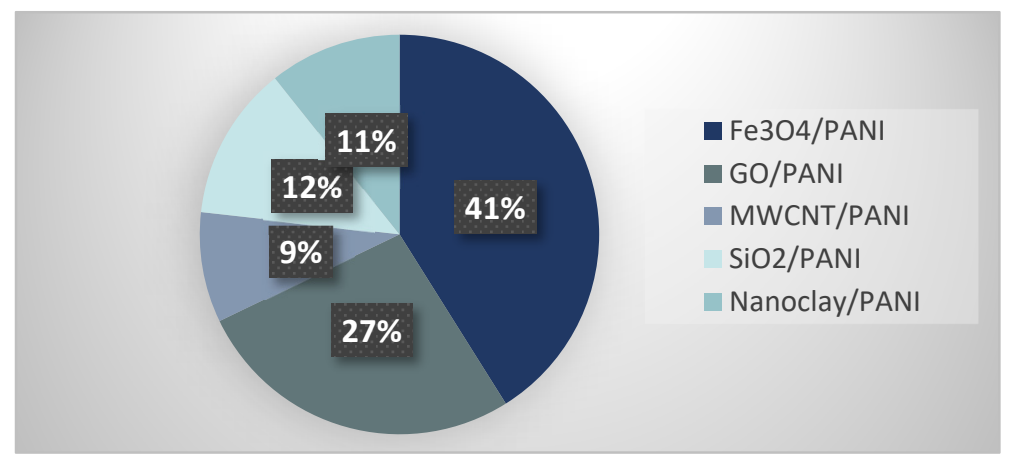

Figure 6. Publication statistics related to different PANI nanocomposites used for the adsorption of metal ions, based on reviewed articles.

\subsection{Metal Oxide or Hydroxide/Polyaniline Composites}

Metal oxide or hydroxide nanoparticles have received great interest in the field of environmental remediation due to their high surface area, small particle size, and specific physical/chemical properties that favor the adsorption and degradation of toxic compounds. However, they show poor performance when used as adsorbents for the removal of heavy metals, because of the challenge of separating them from aqueous solution and reusing them. Rajakumar et al. [42] reported the synthesis of $\mathrm{Mn}_{2} \mathrm{O}_{3}$-doped polyaniline; they observed a decrease in the crystalline nature of $\mathrm{Mn}_{2} \mathrm{O}_{3}$ after coating it with polyaniline. The adsorption performance of the nanocomposite toward $\mathrm{Pb}(\mathrm{II}), \mathrm{Cd}(\mathrm{II})$, and $\mathrm{Ni}$ (II) ions was tested, and the maximum adsorption capacities were 437,480 . and $494 \mathrm{mg} / \mathrm{g}$, respectively, at $\mathrm{pH} 6$, $\mathrm{T}=35^{\circ} \mathrm{C}$ within $60 \mathrm{~min}$. Fast chelation between metal ions and doped metal hydroxyl groups was the main mechanism involved. The uptake of $\mathrm{Pb}$ (II) was also investigated using $\mathrm{Sb}_{2} \mathrm{O}_{3}$-coated polyaniline [43], fabricated via an in situ polymerization method in the presence of hydroxypropyl cellulose as a surfactant. Structural analysis confirmed the existence of $\mathrm{Sb}_{2} \mathrm{O}_{3}$ NPs in the polyaniline matrix, and the nanocomposites had an average size of $55 \mathrm{~nm}$. The uptake process was highly $\mathrm{pH}$-dependent, increasing with decreasing $\mathrm{pH}$; the adsorption capacity at optimum conditions of $\mathrm{pH} 3$ and $\mathrm{t}=30 \mathrm{~min}$ was $21.05 \mathrm{mg} / \mathrm{g}$. Ion exchange and surface complexation were the main mechanisms responsible for the adsorption. In another study, an $\mathrm{Al}_{2} \mathrm{O}_{3} / \mathrm{PANI}$ nanocomposite was prepared via a new one-pot method including simultaneous exfoliation of aluminum nanofibers and electropolymerization of aniline [44]; the nanocomposite displayed a nanofibrous, nanoporous structure with pore diameter in the range of 70-100 $\mathrm{nm}$. The adsorption performance of the nanocomposite was in the following order- $\mathrm{Cu}^{2+}, \mathrm{Pb}^{2+}>\mathrm{Zn}^{2+}>\mathrm{Cd}^{2+}>\mathrm{Ni}^{2+}, \mathrm{Co}^{2+}$ - with significant selectivity toward $\mathrm{Cu}(\mathrm{II})$ and $\mathrm{Pb}$ (II). 
In another attempt, the uptake of arsenic by a nanocomposite based on $\mathrm{ZnO} / \mathrm{CeO}_{2}$ nanoparticles, nanocellulose, and PANI was examined [45]. Microstructural analyses of the prepared material illustrated the successful encapsulation of the metallic nanooxides onto the PANI nanocellulose support, with $\mathrm{CeO}_{2}$ nanoparticles of $1.05 \mathrm{~nm}$ and $\mathrm{ZnO}$ nanoparticles of $10.5 \mathrm{~nm}$. Moreover, AES analysis indicated that $95.75 \%$ of the $\mathrm{ZnO} / \mathrm{CeO}_{2}$ nanoparticles used were successfully embedded onto the nanocellulose. Furthermore, a total of $98.33 \%$ of the $\mathrm{ZnO} / \mathrm{CeO}_{2} /$ nanocellulose nanoparticles were successfully embedded onto the porous polyaniline support. The adsorption efficiency of the nanocomposite was found to remain fairly consistent throughout the $\mathrm{pH}$ range. The adsorption efficiency was above $\sim 95 \%$ under different concentrations and $\mathrm{pH}$ conditions. Moosavian and Moazezi [46] prepared a PANI/ZnO nanocomposite as an adsorbent for the removal of $\mathrm{Cd}(\mathrm{II})$ and $\mathrm{Zn}$ (II). The removal efficiency reached only $35 \%$ and $45 \%$ for $\mathrm{Zn}$ (II) and $\mathrm{Cd}(\mathrm{II})$, respectively; therefore, this nanocomposite is not a highly efficient adsorbent for the removal of heavy metals. In another study, $\mathrm{ZnO} / \mathrm{PANI}$ was synthesized using the same method and tested for the adsorption of $\mathrm{Cr}(\mathrm{VI})$ [47]. The maximum capacity was $139.47 \mathrm{mg} / \mathrm{g}$ at $\mathrm{pH}=2,50^{\circ} \mathrm{C}$ within $120 \mathrm{~min}$. As compared with the previous study, the nanocomposite showed better adsorption performance toward $\mathrm{Cr}(\mathrm{VI})$ than $\mathrm{Cd}(\mathrm{II})$ and $\mathrm{Zn}$ (II). The only difference in the synthesis was the molar ratio of aniline/ $\mathrm{ZnO}$, which was 10 and 5, respectively, suggesting that increasing the percentage of $\mathrm{ZnO}$ in the nanocomposite enhanced its adsorption properties. In another work, a hybrid nanocomposite with a $\mathrm{ZnO}$ core and a xanthan-gum-grafted PANI shell was prepared via an oxidative free radical graft copolymerization method and tested for the uptake of $\mathrm{Cr}(\mathrm{VI})$ [48]. The prepared nanocomposite displayed a high-order crystal structure, as well as a higher thermal stability compared to pure PANI. The nanocomposite exhibited a rough heterogeneous and fibrillar structure with a well-organized dispersion of xanthan gum, PANI, and $\mathrm{ZnO}$ in the matrix. Furthermore, $\mathrm{ZnO}$ nanoparticles with an average size of $31.2 \mathrm{~nm}$ were encapsulated in an orderly manner by XG-PANI. The maximum adsorption capacity was found to be $346.18 \mathrm{mg} / \mathrm{g}$ at pH 2 within $120 \mathrm{~min}$, which is higher than that of $\mathrm{ZnO} / \mathrm{PANI}$, explained by the fact that xanthan gum exhibits a chemical structure with abundant hydroxyl and carboxyl groups that boosted the properties of the nanocomposite.

Another study reported the investigation of $\mathrm{MnO}_{2}$-coated polyaniline nanofibers for the removal of $\mathrm{Cr}(\mathrm{VI})$ [49]. The prepared nanocomposite displayed uniform nanofibers with an average length of around $250-300 \mathrm{~nm}$. The adsorption of $\mathrm{Cr}(\mathrm{VI})$ was highly $\mathrm{pH}$-dependent, with a maximum capacity of $39.3 \mathrm{mg} / \mathrm{g}$ at $\mathrm{pH} 1$ within $60 \mathrm{~min}$. Chen et al. [50]. investigated the synthesis of PANI-doped $\mathrm{TiO}_{2}$ NPs for the removal of a highly concentrated aqueous solution of $\mathrm{Pb}(\mathrm{II}), \mathrm{Zn}(\mathrm{II})$, and $\mathrm{Cu}$ (II) in single- and multiple-metal systems. The structural analysis showed that $\mathrm{TiO}_{2}$ was covered by PANI due to the strong interaction between the two. The adsorption capacities in single-metal systems were $0.594 \mathrm{mmol} / \mathrm{g}$, $0.460 \mathrm{mmol} / \mathrm{g}$, and $0.140 \mathrm{mmol} / \mathrm{g}$, and in multiple-metal systems were $0.547 \mathrm{mmol} / \mathrm{g}$, $0.324 \mathrm{mmol} / \mathrm{g}$, and $0 \mathrm{mmol} / \mathrm{g}$, for $\mathrm{Zn}(\mathrm{II}), \mathrm{Pb}(\mathrm{II})$, and $\mathrm{Cu}(\mathrm{II})$, respectively. This confirms that the nanocomposite had no affinity toward $\mathrm{Cu}$ (II) in the multiple-metal system; therefore, it can be used as an adsorbent with selective properties. Khong et al. [51] investigated the synthesis of multifunctional nanocomposites via the incorporation of $\mathrm{TiO}_{2} \mathrm{NPs}$ and carbon nanotubes (SWNTs, MWNTs) in the presence of hexanoic acid (HA) as a dopant in polyaniline using a template-free method. The surface analysis indicated that the crystallinity and thermal stability of polyaniline was improved after the incorporation of $\mathrm{TiO}_{2}, \mathrm{MWNTs}$, and SWNTs. The adsorption of heavy metals onto PANI/HA/ $/ \mathrm{TiO}_{2} / \mathrm{SWNTs}$ showed a removal efficiency with the ascending order of $\mathrm{Pb}$ (II) $<\mathrm{Cd}$ (II) $<\mathrm{Cu}$ (II) $<\mathrm{Fe}$ (III). The nanocomposite showed potential recyclability up to 7 cycles and good selectivity for Fe(III) with a high removal efficiency in the presence of other heavy metals.

In a study conducted by Sahu et al. [52], a thorium oxide nanoparticle core-coated polyaniline nanocomposite synthesized via an in situ polymerization method was applied to remove $\mathrm{Cr}(\mathrm{VI})$. The surface of the prepared nanocomposite was uniformly coated with amorphous PANI, and each distinct $\mathrm{ThO}_{2} \mathrm{NP}$ was coated with a PANI shell. The 
nanocomposite exhibited a good thermal stability, even beyond $700{ }^{\circ} \mathrm{C}$, as well as a high specific surface area of $86.98 \mathrm{~m}^{2} / \mathrm{g}$ and low average pore diameter of $3.9 \mathrm{~nm}$, with a pore distribution in the nanoscale range, which implied its highly porous nature. The adsorbent displayed a maximum adsorption capacity of $141 \mathrm{mg} / \mathrm{g}$ under the optimal conditions of $\mathrm{pH} 5, \mathrm{~T}=323 \mathrm{~K}$, and $\mathrm{t}=60 \mathrm{~min}$ as equilibrium time. The mechanisms of $\mathrm{Cr}(\mathrm{VI})$ adsorption by $\mathrm{ThO}_{2} /$ PANI were due to the anionic adsorption of $\mathrm{Cr}(\mathrm{VI})$ via electrostatic interaction and adsorption, coupled with the partial reduction of $\mathrm{Cr}(\mathrm{VI})$ to $\mathrm{Cr}(\mathrm{III})$ (Figure 7). Moreover, the $\mathrm{ThO}_{2}$ /PANI nanocomposite showed good stability and potential reusability.

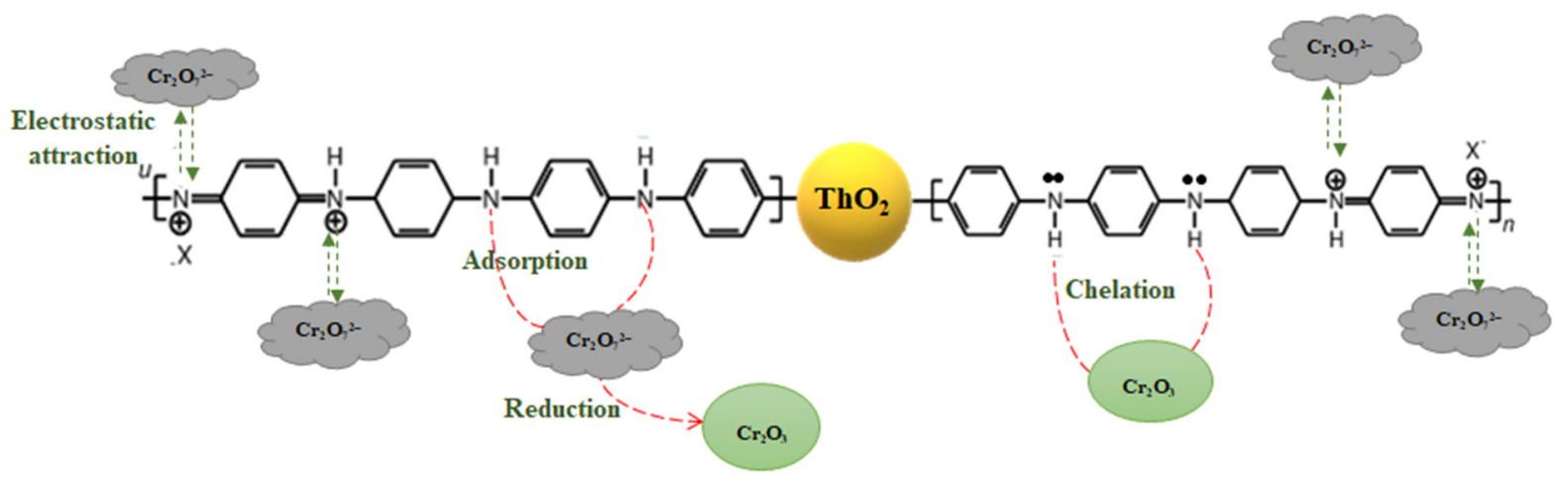

Figure 7. Proposed mechanism of $\mathrm{Cr}(\mathrm{VI})$ adsorption onto a $\mathrm{ThO}_{2}$-PANI nanocomposite.

Metal hydroxide/PANI nanocomposites have also been investigated for the adsorption of heavy metals. In this vein, Bhaumik et al. [53] investigated the removal of $\mathrm{Cr}(\mathrm{VI})$ by polyaniline-coated $\mathrm{Ni}(\mathrm{OH})_{2}$. In brief, PANI nanotubes were prepared via a self-assembly method using 2-naphtalene sulfonic acid as a dopant; afterwards, $\mathrm{Ni}(\mathrm{OH})_{2} \mathrm{NPs}$ were deposited on the surface of PANI nanotubes via wet chemical reaction in the presence of nickel chloride, hydrazine hydrate, and $\mathrm{NaOH}$ at $60{ }^{\circ} \mathrm{C}$. The composite exhibited a nanotubular structure with an average diameter of 150-230 nm. However, the deposition of $\mathrm{Ni}(\mathrm{OH})_{2}$ on its surface reduced the visibility of the tubular structure of the nanocomposite. The nanocomposite exhibited an average pore diameter of $21.1 \mathrm{~nm}$, with a total pore volume of $0.141 \mathrm{~cm}^{3} / \mathrm{g}$ and a specific surface area of $26.85 \mathrm{~m}^{2} / \mathrm{g}$-higher than that of PANI. It displayed a higher adsorption capacity of $625 \mathrm{mg} / \mathrm{g}$ at $\mathrm{pH} 4$ and $\mathrm{T}=25^{\circ} \mathrm{C}$ compared with its PANI nanotube counterpart. We et al. [54] synthesized iron-oxide/hydroxide-NP-coated phytic acid polyaniline. The nanocomposite surface contained a large number of amine and imine groups, and exhibited a specific surface area of $23.38 \mathrm{~m}^{2} / \mathrm{g}$-lower than that of FeOOH $\left(104.5 \mathrm{~m}^{2} / \mathrm{g}\right)$. Batch adsorption performance was tested toward U(VI), with a maximum adsorption capacity of $555.8 \mathrm{mg} / \mathrm{g}$ at $\mathrm{pH} 8,298 \mathrm{~K}$, and fast equilibrium in $5 \mathrm{~min}$. Moreover, the coexisting ions were found to have an insignificant effect on the adsorption of $U(V I)$, implying that the composite is a potential selective adsorbent for U(VI).

\subsection{Polyaniline/Magnetic Nanoparticles}

Magnetic nanoparticles have recently attracted considerable attention as effective materials in the removal of heavy metals from aqueous solution, owing to their high surface area, facile functionalization, chemical and physical stability, designable structure, and superparamagnetic properties, which offer a potential advantage to overcome the separation challenge via a simple and compact process through the application of an external magnetic field. Spinel ferrite nanoparticles-including iron-oxide-based materials such as maghemite $\left(\gamma-\mathrm{Fe}_{2} \mathrm{O}_{3}\right)$, hematite $\left(\alpha-\mathrm{Fe}_{2} \mathrm{O}_{3}\right)$, and magnetite $\left(\mathrm{Fe}_{3} \mathrm{O}_{4}\right)$-have been fully studied owing to their low toxicity, relatively high saturation magnetization at room temperature, and biocompatibility. However, they are susceptible to acid conditions, air oxidation, and aggregation in aqueous systems [55]. As a result, the synthesis of magnetic polyaniline nanocomposite materials is an effective strategy to prevent particles from being massed and oxidized. Different magnetic polyaniline nanocomposites have been synthesized using 
different methods. Well-defined core-shell nanocomposites can be synthesized using an in situ polymerization method of aniline on the surface of magnetic NPs in the presence of an oxidant in acidic media at $0-5^{\circ} \mathrm{C}$, or by microemulsion polymerization in the presence of structural direct agents, which can act as soft templates based on their self-assembly-such as p-toluenesulfonic acid (pTSA), sodium dodecyl sulfate (SDS), cetyltrimethylammonium bromide (CTAB), and tartaric acid.

$\mathrm{Gu}$ et al. [56] reported the synthesis of $\mathrm{Fe}_{3} \mathrm{O}_{4} / \mathrm{PANI}$ nanocomposites for the removal of $\mathrm{Cr}(\mathrm{VI})$ from aqueous solution. The microstructure characterization showed that the nanocomposites' surface became rougher, and a thin PANI layer was observed surrounding the $\mathrm{Fe}_{3} \mathrm{O}_{4}$ NPs. After adsorption of $\mathrm{Cr}(\mathrm{VI})$, the nanocomposites exhibited similar magnetic properties, confirming that PANI effectively protected the $\mathrm{Fe}_{3} \mathrm{O}_{4} \mathrm{NPs}$ from dissolution, although a slight decrease in the specific surface area was observed. The synthesized material performed a fast and efficient removal of $\mathrm{Cr}(\mathrm{VI})$ in a wide $\mathrm{pH}$ range. The surface analyses after adsorption revealed that the surface reduction of $\mathrm{Cr}(\mathrm{VI})$ to $\mathrm{Cr}(\mathrm{III})$ and electron attraction between $\mathrm{NH}_{2}$ of $\mathrm{PANI}$ and $\mathrm{CrO}_{4}{ }^{2-}$ were the main mechanisms of $\mathrm{Cr}(\mathrm{VI})$ adsorption, and the oxidation form of PANI had partially changed from emeraldine salt to pernigraniline. In another work, the uptake of $\mathrm{Cr}(\mathrm{VI})$ using $\mathrm{Fe}_{3} \mathrm{O}_{4} / \mathrm{PANI}$ microspheres was examined [57]. The microstructural analysis illustrated that $\mathrm{Fe}_{3} \mathrm{O}_{4} \mathrm{NPs}$ were composed of microspheres with a diameter of $250 \mathrm{~nm}$ and nanospheres of 30-50 nm after coating with PANI. The surface was coarse and the PANI/ $\mathrm{Fe}_{3} \mathrm{O}_{4}$ spheres increased in diameter up to $310 \mathrm{~nm}$ with a well-defined core-shell structure. Chavez-Guiajardo et al. [58] studied the removal of $\mathrm{Cu}(\mathrm{II})$ and $\mathrm{Cr}(\mathrm{VI})$ ions from aqueous media using a polyaniline maghemite nanocomposite (PANI $/ \gamma-\mathrm{Fe}_{2} \mathrm{O}_{3}$ ). The nanocomposite was composed of several $\mathrm{Fe}_{3} \mathrm{O}_{4} \mathrm{NPs}$ coated with PANI, with a particle size distribution that varied from $51 \mathrm{~nm}$ to $142 \mathrm{~nm}$, and an average diameter of $(87 \pm 32) \mathrm{nm}$. The composite exhibited the highest adsorption capacity toward $\mathrm{Cr}(\mathrm{VI})$, of $195 \mathrm{mg} / \mathrm{g}$, compared to $107 \mathrm{mg} / \mathrm{g}$ obtained for $\mathrm{Cu}(\mathrm{II})$. Ebrahim et al. [59] reported the synthesis of a polyaniline/akageneite nanocomposite by mechanically mixing $70 \%$ polyaniline prepared via in situ polymerization and $30 \%$ akageneite prepared via a coprecipitation method. According to their findings, the adsorption of $\mathrm{Cr}(\mathrm{VI})$ onto the nanocomposite was highly $\mathrm{pH}$-dependent, with a high removal capacity in a wide $\mathrm{pH}$ range, from 2 to 9 . The equilibrium rate was achieved rapidly-within $5 \mathrm{~min}$-with a maximum adsorption capacity of $17.5 \mathrm{mg} / \mathrm{g}$ at $\mathrm{pH}$ 2. The $\mathrm{NC}$ was tested to remove $\mathrm{Cr}(\mathrm{VI})$ from a leather tanning wastewater sample, and exhibited a removal efficiency of $93.4 \%$ at $\mathrm{pH}$ 2. In another attempt, Sadeghi et al. [60] synthesized a nanocomposite adsorbent based on magnetic $\mathrm{Fe}_{3} \mathrm{O}_{4}$ NPs coated with polyaniline for the removal of $\mathrm{Pb}$ (II) ions. The adsorption results showed that the maximum adsorption capacity was $111.11 \mathrm{mg} / \mathrm{g}$ at $\mathrm{pH}$ 9, achieved in $60 \mathrm{~min}$; however, an increase in the absorbent dosage was found to have a negative effect on the adsorption of $\mathrm{Pb}(\mathrm{II})$. Lyu et al. [61] investigated the synthesis of a 3D hierarchical coral-like micro/nanostructural polyaniline labeled CL-PANI and two magnetic nanocomposites that exhibited excellent adsorption and easy separation performance with two different modes: a CL-PANI core coated a shell of $\mathrm{Fe}_{3} \mathrm{O}_{4} \mathrm{NPs}$, and a core of $\mathrm{Fe}_{3} \mathrm{O}_{4}$ NPs protected by a CL-PANI shell. Surface analysis of the prepared CL-PANI@ $\mathrm{Fe}_{3} \mathrm{O}_{4}$ illustrated that CL-PANI was well coated by $\mathrm{Fe}_{3} \mathrm{O}_{4}$ NPs with a diameter of $10 \mathrm{~nm}$ and a uniform distribution, confirmed by the presence of lattice fingers with an interplanar distance of $0.3 \mathrm{~nm}$, correlated to the magnetite phase. The CL-PANI@ $\mathrm{Fe}_{3} \mathrm{O}_{4}$ depicted a 3D-like-structure with no obvious magnetite on the surface. However, the lattice fingers with an interplanar distance of $0.3 \mathrm{~nm}$ could still be observed, implying that $\mathrm{Fe}_{3} \mathrm{O}_{4}$ was confined inside the nanocomposite. CL-PANI modified with $\mathrm{Fe}_{3} \mathrm{O}_{4}$ NPs showed a decreased adsorption capacity; on the other hand, the mechanism studies found that the nanocomposites produced more active sites for immobilizing the reduced $\mathrm{Cr}(\mathrm{III})$ ions and facilitated the separation of the adsorbent from the solution. Based on the comparison of the nanocomposites' properties, $\mathrm{Fe}_{3} \mathrm{O}_{4} @ \mathrm{CL}-\mathrm{PANI}$ was found to be more promising in the practical treatment of $\mathrm{Cr}(\mathrm{VI})$, displaying higher adsorption and chromium reduction capacity. Moreover, the as-synthesized adsorbents exhibited high regeneration capacity 
and stability; as a result, less iron leaching was detected from $\mathrm{Fe}_{3} \mathrm{O}_{4} @ \mathrm{CL}-\mathrm{PANI}$ than from CL-PANI@ $\mathrm{Fe}_{3} \mathrm{O}_{4}$, suggesting that coating the magnetite cores with PANI shell could further inhibit the corrosion of $\mathrm{Fe}_{3} \mathrm{O}_{4}$ particles.

Agrawal and Singh [62] prepared a $\mathrm{NiFe}_{2} \mathrm{O}_{4} /$ PANI nanocomposite via the in situ polymerization of aniline and $5 \%$ wt $\mathrm{NiFe}_{2} \mathrm{O}_{4}$ and evaluated it for its $\mathrm{Cr}(\mathrm{VI})$ adsorption. The chemical structure and morphology of the prepared $\mathrm{NiFe}_{2} \mathrm{O}_{4} \mathrm{NPs}$ revealed a more crystalline structure compared to the nanocomposite. The maximum capacity obtained from the Langmuir isotherm was $12.19 \mathrm{mg} / \mathrm{g}$ at $\mathrm{pH}$ 2. In another study, a polyaniline nanofiber/zero-valent iron $\mathrm{Fe}^{0}\left(\mathrm{Fe}^{0} / \mathrm{PANI}\right)$ nanocomposite was synthesized via the chemical oxidative polymerization of aniline monomer in the presence of $\mathrm{FeCl}_{3}$, followed by the addition of $\mathrm{FeCl}_{2} / \mathrm{FeCl}_{3}$, after which $\mathrm{NaBH} 4$ was added in order to embed $\mathrm{Fe}^{0} \mathrm{NPs}$ on the PANI nanofibers [63]. The composite exhibited a rougher surface compared to polyaniline, with a particle diameter ranging from 50 to $150 \mathrm{~nm}$, which confirmed that $\mathrm{Fe}^{0} \mathrm{NPs}$ with an average diameter of $14.27 \mathrm{~nm}$ were successfully deposited onto the PANI nanofibers. The $\mathrm{Fe}^{0} /$ PANI composite revealed a specific surface area of $42.58 \mathrm{~m}^{2} / \mathrm{g}$-higher than that of PANI and $\mathrm{Fe}^{0}$ NPs. The adsorption kinetics of $\mathrm{Cr}(\mathrm{VI})$ and $\mathrm{As}(\mathrm{V})$ were fast for both pollutants, and the maximum adsorption capacities were 42.37 and $434.78 \mathrm{mg} / \mathrm{g}$ for $\mathrm{As}(\mathrm{V})$ and $\mathrm{Cr}(\mathrm{VI})$, respectively. Singh and Rachna [64] synthesized a $\mathrm{CuFe}_{2} \mathrm{O}_{4} / \mathrm{PANI}$ nanocomposite via a simple polymerization method for the removal of $\mathrm{Cr}(\mathrm{VI})$ from aqueous solution. The equilibrium isotherm showed a good fit with the Langmuir isotherm equation, with a maximum adsorption capacity of $676.08 \mathrm{mg} / \mathrm{g}$ at $\mathrm{pH} 2$. In addition, the as-synthesized nanocomposite was reused for four consecutive cycles, with a removal capacity of $70 \%$.

\subsection{Multifunctional Magnetic Polyaniline Nanocomposites}

Magnetic mesoporous carbon-coated PANI prepared via the incorporation of carbon precursors, an SBA-15 template, and $\mathrm{FeCl}_{3}$, followed by in situ polymerization, was investigated for the adsorption and reduction of $\mathrm{Cr}(\mathrm{VI})$ [65]. The nanocomposite exhibited a high removal efficiency of $92 \%$, with a maximum adsorption capacity of $172.33 \mathrm{mg} / \mathrm{g}$ at pH 2 within $120 \mathrm{~min}$. The nanocomposites could be well regenerated and maintained at over $90 \% \mathrm{Cr}(\mathrm{VI})$ adsorption efficiency after seven cycles. In another study, Tang et al. [66] synthesized a magnetic mesoporous silica-coated polyaniline composite for the removal of $\mathrm{Cr}(\mathrm{VI})$. The prepared material exhibited a cage-like, uniform, mesoporous structure, and showed a maximum adsorption capacity of $193.85 \mathrm{mg} / \mathrm{g}$ at $\mathrm{pH} 2$.

A superparamagnetic nanocomposite of polyaniline thiacalix[4] arene labeled $\mathrm{Fe}_{3} \mathrm{O}_{4} @$ PANI-AmAZoTCA was synthesized in three steps: First, functionally polymerizable thiacalixarene (AmAZoTCA) was synthesized via stepwise addition of ethyl acetate and azodiamine to TCA[4], followed by the synthesis of the copolymer PANIAmAZoTCA[4] through copolymerization in acidic media in the presence of APS [67]. Afterwards, the $\mathrm{Fe}_{3} \mathrm{O}_{4} @ P A N I-A m A Z o T C A$ was obtained via in situ coprecipitation of a mixed solution of Fe(II), Fe(III), and PANI-AmAZoTCA[4]. The composite exhibited a semicrystalline morphology with $\mathrm{Fe}_{3} \mathrm{O}_{4}$ NPs in spherical particle form, with a homogeneous 30-40 $\mathrm{nm}$ size distribution. The adsorption performance toward $\mathrm{Cu}(\mathrm{II}), \mathrm{Cd}(\mathrm{II})$, $\mathrm{Co}(\mathrm{II})$, and $\mathrm{Cr}(\mathrm{III})$ showed great adsorption capacities of 312.5, 285.7, 312.5, and $303 \mathrm{mg} / \mathrm{g}$, respectively.

The adsorption of $\mathrm{Cu}(\mathrm{II})$ using a multifunctional magnetic nanocomposite with a polystyrene core, transition layer of $\mathrm{Fe}_{3} \mathrm{O}_{4} \mathrm{NPs}$, and PANI shell-designated PS/ $\mathrm{Fe}_{3} \mathrm{O}_{4} @$ PANI-was investigated by $\mathrm{Li}$ et al. [68]. First, $\mathrm{PS} / \mathrm{Fe}_{3} \mathrm{O}_{4}$ was prepared by electrostatic attraction at $\mathrm{pH} 3$ between negatively charged polystyrene prepared via emulsifier-free emulsion polymerization and positively charged $\mathrm{Fe}_{3} \mathrm{O}_{4}$ nanoparticles obtained by chemical coprecipitation, followed by the coating of the PANI on the surface of the PS/ $\mathrm{Fe}_{3} \mathrm{O}_{4}$ using a swelling-diffusion-interfacial polymerization method. The nanocomposite displayed a uniform size and spherical outline. The adsorption results revealed excellent adsorption capacity for $\mathrm{Cu}(\mathrm{II})(181.5 \mathrm{mg} / \mathrm{g})$ at $\mathrm{pH}$ 5. Zhang et al. [69] developed a multifunctional magnetic adsorbent containing $\mathrm{MnO}_{2}$ and $\mathrm{PANI}$ - designated $\mathrm{Fe}_{3} \mathrm{O}_{4} / \mathrm{PANI} / \mathrm{MnO}_{2}$ - for 
the removal of $\mathrm{Cd}$ (II). In short, $\mathrm{Fe}_{3} \mathrm{O}_{4} \mathrm{NPs}$ were synthesized via a solvothermal method, after which PANI was coated on the surface of $\mathrm{Fe}_{3} \mathrm{O}_{4}$ NPs via the oxidative polymerization of aniline in the presence of $\mathrm{PVP}(\mathrm{K} 30)$ in acidic medium, using APS as an oxidant, at room temperature, and sonicated for various lengths of time. $\mathrm{MnO}_{2} \mathrm{NPs}$ were deposited on the surface of $\mathrm{Fe}_{3} \mathrm{O}_{4} / \mathrm{PANI}$ via wet chemical reaction using $\mathrm{KMnO}_{4}$ at $0-5{ }^{\circ} \mathrm{C}$, leading to the formation of an $\mathrm{Fe}_{3} \mathrm{O}_{4} / \mathrm{PANI} / \mathrm{MnO}_{2}$ hybrid core-shell. The prepared material exhibited a uniform spherical nanostructure with particles of $300 \mathrm{~nm}$ in diameter, and a hierarchical nanostructure where the surfaces were covered with numerous interconnected $\mathrm{MnO}_{2}$ nanoflakes. Batch experiments indicated a maximum adsorption capacity of $154 \mathrm{mg} / \mathrm{g}$ at $\mathrm{PH}$ 6.3. Chao et al. [70] synthesized a magnetic, chitosan-core-coated, polyaniline shell $\mathrm{Fe}_{3} \mathrm{O}_{4} / \mathrm{CS} @ P A N I$ nanoadsorbent for the removal of $\mathrm{Cr}(\mathrm{VI})$; the adsorption was fast, and the maximum adsorption capacity reached $186.6 \mathrm{mg} / \mathrm{g}$ in a strong acidic medium of $\mathrm{pH}$ 2. In addition, no leaching during the adsorption was observed; thus, chitosan and PANI coatings protected the $\mathrm{Fe}_{3} \mathrm{O}_{4}$ core from dissolution and enhanced the adsorption. The as-synthesized adsorbents exhibited high regeneration capacity and stability of more than $90 \%$ in the removal of $\mathrm{Cr}(\mathrm{VI})$ after five consecutive cycles.

Kumar et al. [71] prepared a multifunctional GO/ $\mathrm{SiO}_{2} @ P A N I$ nanocomposite via the in situ polymerization of aniline in the presence of $\mathrm{SiO}_{2}$ and $\mathrm{GO}$ for the adsorption of $\mathrm{Cu}(\mathrm{II})$ and $\mathrm{Cr}(\mathrm{VI})$. The nanocomposite showed the highest adsorption toward $\mathrm{Cr}(\mathrm{VI})$, with a maximum adsorption capacity of $512.47-540.17 \mathrm{mg} / \mathrm{g}$, compared to $\mathrm{Cu}(\mathrm{II})$, with a maximum adsorption of $258.27-314.11 \mathrm{mg} / \mathrm{g}$, at $30-50{ }^{\circ} \mathrm{C}$, respectively. Taleb et al. [72] investigated a $\mathrm{SiO}_{2} / \mathrm{CuFe}_{2} \mathrm{O}_{4} @ \mathrm{PANI}$ composite for the removal of $\mathrm{Mn}(\mathrm{II}), \mathrm{Fe}(\mathrm{II})$, and $\mathrm{Cu}(\mathrm{II})$; the composite displayed compacted and agglomerated particles of cubic $\mathrm{CuFe}_{2} \mathrm{O}_{4} \mathrm{NPs}$ and thin layers of PANI with different shapes in contact with the spherical $\mathrm{SiO}_{2} \mathrm{NPs}$. The maximum adsorption capacities were 285.71, 416.67, and $454.55 \mathrm{mg} / \mathrm{g}$ for $\mathrm{Cu}(\mathrm{II}), \mathrm{Fe}(\mathrm{II})$, and $\mathrm{Mn}(\mathrm{II})$, respectively, at $\mathrm{pH} 5$ within $300 \mathrm{~min}$.

\subsection{Carbon-Based Nanomaterial/PANI Nanocomposites}

Carbon-based nanomaterials-including carbon nanotubes, as well as graphene and its derivatives-have drawn wide attention in recent years as novel materials for environmental applications due to their unique chemical and physical properties, as well as their high surface-area-to-volume ratio, controlled pore size distribution, and manipulable surface chemistry. The surfaces of these materials contain some functional groups, which play an important role in the adsorption process. Therefore, in order to obtain suitable structures, enhanced adsorptive capacities, and abundant functional groups, carbon nanomaterial/PANI composites have been investigated.

\subsubsection{PANI/Graphene Derivatives}

Currently, there is great interest in graphene derivatives. GO is the oxidized form of graphene that is commonly prepared by the Hummers method, and includes a large amount of oxygen-containing functional groups, epoxy and hydroxyl groups in the basal planes, and carboxyl acid groups at the edge. GO is characterized by its high mechanical strength and a theoretical specific surface area of around $2630 \mathrm{~m}^{2} / \mathrm{g}$, making it a suitable material for the efficient removal of heavy metal ions from aqueous solution. However, GO has high affinity toward water, implying the possibility of leaching and high cost of synthesis. Moreover, the available functional groups on GO are very limited. Therefore, the introduction of new functional groups on GO's surface using polyaniline polymer leads to an efficient nanocomposite with remarkable adsorption properties. Aniline is known to be a good electron donor, while graphene is a strong electron acceptor. A previous study reported that the interaction between GO and PANI occurs though chemical bonding, hydrogen bonding, $\pi-\pi$ interactions, and electrostatic interactions [73].

In this context, Zhang et al. [74] reported the synthesis of polyaniline nanorod-dotted graphene oxide nanosheets via dilute polymerization below $-20^{\circ} \mathrm{C}$. The composite exhibited a high $\mathrm{Cr}(\mathrm{VI})$ adsorption capacity of $1149.4 \mathrm{mg} / \mathrm{g}$, coupled with reduction into $\mathrm{Cr}(\mathrm{III})$. 
Moreover, the synthesized nanocomposite was stable and environmentally friendly, with high regeneration capacity and recyclability, and no obvious decrease in capacity even after five cycles. In another study, Fan et al. [75] reported the synthesis of a three-dimensional polyaniline graphene oxide PANI/GO material. The prepared material exhibited a loose and spongy macroscale porous structure, with sponges showing a rough and shaggy structure with numerous pores. The optimal weight ratio of PANI to GO was found to be $0.64: 1$. The adsorption performance toward $\mathrm{Hg}$ (II) showed a maximum adsorption capacity of $80.7 \mathrm{mg} / \mathrm{g}$ at $\mathrm{pH}$ 5. In addition, the presence of coexisting ions weakly affected the adsorption of $\mathrm{Hg}(\mathrm{II})$. In another attempt, a polyaniline nanocomposite coated with graphene sheets was prepared via the in situ polymerization of aniline on the surface of prepared GO, followed by reduction using borohydride [76]. The nanocomposites displayed a coral-like dendritic nanofiber morphology similar to that of PANI. The adsorption performance was tested toward $\mathrm{Cr}(\mathrm{VI})$, and the nanocomposite with 10\% GO loading showed a maximum adsorption capacity of $192 \mathrm{mg} / \mathrm{g}$ under optimal conditions of pH 2 and $20 \mathrm{~min}$ of equilibrium time. In another study, Ramezanzadeh et al. [77] reported the synthesis of graphene oxide nanosheets coated with highly crystalline PANI nanofibers for the removal of $\mathrm{Zn}$ (II). The surface analysis indicated that PANI nanofibers were successfully linked to the GO and successfully enveloped the graphene oxide surface. Microstructural analyses indicated a rough and uneven morphology, implying the deposition of fine PANI nanofibers on the GO surface. The adsorption capacity was $1160 \mathrm{mg} / \mathrm{g}$ under optimal conditions of $\mathrm{pH}$, within $20 \mathrm{~min}$. The UV-Visible spectral analysis of GO/PANI after adsorption displayed that in spite of the high adsorption, the stability of the PANI/GO particles was damaged, leading to their agglomeration and sedimentation. In another attempt, Zong et al. [40] reported the synthesis of an $\mathrm{Fe}_{3} \mathrm{O}_{4} / \mathrm{GO} / \mathrm{PANI}$ nanocomposite using a low-temperature plasma technique, for the adsorption of $\mathrm{Cd}(\mathrm{II})$ in single and binary systems with phenol. The maximum adsorption capacity was $2.87 \mu \mathrm{mol} / \mathrm{g}$, due to chemical complexation. In terms of $\mathrm{pH}$, at lower $\mathrm{pH}$ values the mechanisms of $\mathrm{Cd}(\mathrm{II})$ uptake were due to ion exchange and/or surface complexation, although at high $\mathrm{pH}$ values adsorption was dominant. In the binary system, the presence of phenol led to an increase in the adsorption of Cd(II) onto the composites; however, the adsorption of phenol was not influenced by $\mathrm{Cd}$ (II) ions coexisting in binary solution systems.

Yang et al. [78] investigated the removal of $\mathrm{Pb}(\mathrm{II})$ using a novel lignosulfonate graphene oxide polyaniline LS-GO-PANI nanocomposite. The maximum adsorption capacity was $216.4 \mathrm{mg} / \mathrm{g}$ at $\mathrm{pH} 5$ and $\mathrm{T}=30^{\circ} \mathrm{C}$. The synergistic effect of the functional groups on LS-GOPANI played the key role in $\mathrm{Pb}$ (II) adsorption. In another study, Liu et al. [79] introduced magnetite nanoparticles onto the surface of a PANI/GO nanocomposite in order to facilitate the separation of the material after adsorption. The nanocomposite exhibited a rougher, wrinkled structure after the deposition of PANI, with the presence of $\mathrm{Fe}_{3} \mathrm{O}_{4} \mathrm{NPs}$ on the surface. It was reported that the adsorption of $\mathrm{Cu}(\mathrm{II})$ was fast, strongly dependent on $\mathrm{pH}$, and independent of ionic strength, with a calculated removal capacity of $101.94 \mathrm{mg} / \mathrm{g}$ at $\mathrm{pH} 5.8$ and $\mathrm{T}=65^{\circ} \mathrm{C}$. In another work, a PANI/rGO/ $\mathrm{Fe}_{3} \mathrm{O}_{4}$ nanocomposite was prepared by $\mathrm{Li}$ et al. [80] via polymerization of aniline monomers on the surface of solvothermally prepared $\mathrm{rGO} / \mathrm{Fe}_{3} \mathrm{O}_{4}$. The nanocomposite with 30\% GO was found to exhibit the highest adsorption capacity for $\mathrm{Hg}(\mathrm{II})$ and magnetic properties for easy magnetic recovery. The maximum adsorption capacity was calculated as $460.24 \mathrm{mg} / \mathrm{g}$ at $\mathrm{pH} 6.5$ within $24 \mathrm{~h}$.

\subsubsection{Carbon Nanotubes/PANI}

An effective nanocomposite consisting of MWCNT-coated polyaniline-designated PANI/MWCNTs - was investigated via a plasma-induced polymerization method [81]. The prepared material illustrated that the MWCNTs' surface became rougher and attached to many branches, with more stacking morphology, after being coated by PANI. The composite displayed an adsorption capacity toward $\mathrm{Pb}$ (II) of $22.2 \mathrm{mg} / \mathrm{g}$. Moreover, the removal of $\mathrm{Pb}(\mathrm{II})$ was highly $\mathrm{pH}$-dependent, increasing with increasing $\mathrm{pH}$, whereas the presence of ionic strength had no effect on the adsorption. In another study, 
Kumar et al. [82] worked on the uptake of $\mathrm{Cr}(\mathrm{VI})$ by a dodecylbenzene sulfonic acid (DBSA)-doped polyaniline/multiwalled carbon nanotubes nanocomposite prepared using a microemulsion polymerization method. The prepared material displayed a rough, rope-like structure of polyaniline-coated MWCNTs. The adsorption of $\mathrm{Cr}(\mathrm{VI})$ was mainly temperature- and $\mathrm{pH}$-dependent. Furthermore, ionic strength significantly affected the adsorption due to the competition at the active sites between $\mathrm{Cr}(\mathrm{VI})$ and anions. The maximum adsorption capacity was $55.55 \mathrm{mg} / \mathrm{g}$ at $\mathrm{T}=30{ }^{\circ} \mathrm{C}$ and $\mathrm{pH} 2$. The same authors evaluated the capability of functionalized, multiwalled carbon nanotube polyaniline prepared via an in situ oxidative polymerization method, which was then doped with para-toluenesulfonic acid-designated pTSA-Pani@CNT_for the removal of $\mathrm{Cr}(\mathrm{VI})$ ions from aqueous media [83]. The as-prepared composite displayed a rough surface and interconnected thin fibers, along with the polymerization of aniline between the wedges, leading to the formation of an interconnected network-like structure, as well as an interwoven fibrous and porous structure. The maximum adsorption capacity was $166.66 \mathrm{mg} / \mathrm{g}$ at $\mathrm{pH}$ 2. In another study, Ansari et al. [84] reported the synthesis of MCNT-GO combined with polyaniline and doped with para-toluenesulfonic acid (pTSA). The nanocomposite showed that the diameter of MWCNTs increased with the observance of network-like, interwoven, fibrous structures after coating with GO and PANI, while aniline was polymerized between the wedges of the MWCNTs and on the tube surfaces with the space in the network of micro- and nanometer pores. The nanocomposite had an adsorption capacity toward $\mathrm{Cr}(\mathrm{VI})$ of $142.87 \mathrm{mg} / \mathrm{g}$ at $\mathrm{pH} 2$ and $30^{\circ} \mathrm{C}$, whereas the equilibrium was achieved within $500 \mathrm{~min}$ - explained by the fact that the adsorption was controlled by boundary and intraparticle diffusion.

\subsection{Silica/Polyaniline Nanocomposite}

Silica and ordered mesoporous silica have been extensively studied for their widespread application in areas such as catalysis and environmental protection. The significance of these materials arises from their pore sizes, which allow controlled accessibility to large molecules, depending on pore geometry. Moreover, they have an open pore structure, which allows improved access and transfer of target molecules compared to the bottleneck pores of amorphous materials, which resist molecular diffusion to the adsorption sites. The modification of these materials with PANI support is of great interest, and many researchers have worked on PANI/mesoporous silica composites to make adsorbents to remove toxic ions from water and wastewater.

A PANI $/ \mathrm{SiO}_{2}$ nanocomposite was synthesized via the in situ polymerization of aniline monomers on the surface of commercial $\mathrm{SiO}_{2} \mathrm{NPs}$ [85]. The maximum removal capacity of $\mathrm{Cr}(\mathrm{VI})$ was $63.41 \mathrm{mg} / \mathrm{g}$ within $60 \mathrm{~min}$ at $303 \mathrm{~K}, \mathrm{pH} 4.2$, and $50 \mathrm{mg} / \mathrm{L}$ as the initial concentration of $\mathrm{Cr}(\mathrm{VI})$ ions. Ion exchange and adsorption-coupled reduction were the main mechanisms of $\mathrm{Cr}(\mathrm{VI})$ adsorption onto $\mathrm{PANI} / \mathrm{SiO}_{2}$. In another work, a polyaniline/hexagonal mesoporous silica (HMS) nanocomposite was synthesized by Javadian et al. [86] using a microemulsion polymerization method in the presence of hydroxypropyl cellulose as a surfactant. The PANI was successfully grafted onto the surface of silica with a spherical and uniform structure. The maximum adsorption capacity of $\mathrm{Ni}$ (II) was $257.17 \mathrm{mg} / \mathrm{g}$ at a concentration of $300 \mathrm{mg} / \mathrm{L}$ of $\mathrm{Ni}(\mathrm{II})$ solution. A polyaniline/polypyrrole/hexagonal-type mesoporous silica nanocomposite was also investigated for the removal of $\mathrm{Cd}(\mathrm{II})$ [87]. The composite was fabricated based on the oxidative polymerization of aniline and pyrrole monomers and HMS nanoparticles, in the presence of hydroxypropyl cellulose as a surfactant. The maximum adsorption capacity was $384.61 \mathrm{mg} / \mathrm{g}$ at $\mathrm{pH} 8$ within $8 \mathrm{~min}$, and the nanocomposite exhibited good regeneration capacity.

Mahmoud et al. [88] prepared two novel nanocomposites consisting of nanosilica functionalized with nanopolyaniline and crosslinked nanopolyaniline through a simple and green method based on a solid-solid reaction between nanosilica and nanopolyaniline or crosslinked nanopolyaniline. The adsorption performance was tested for the removal of $\mathrm{Cu}(\mathrm{II}), \mathrm{Cd}(\mathrm{II}), \mathrm{Hg}(\mathrm{II})$, and $\mathrm{Pb}(\mathrm{II})$ ions. The nanocomposite prepared with crosslinked 
nanopolyaniline was found to be more efficient in the removal of $\mathrm{Cd}, \mathrm{Hg}$, and $\mathrm{Pb}$, while the other composite exhibited a higher $\mathrm{Cu}$ (II) adsorption capacity. The presence of coexisting cations indicated strong interference in the adsorption process. In addition, the nanocomposites were successfully tested for the adsorption of heavy metals from drinking water, seawater, and wastewater samples, with excellent recovery.

\subsection{Nanoclay/PANI Nanocomposites}

Nanoclays have been studied in various disciplines, owing to their wide availability, relatively low cost, and low environmental impact. Nanoclays are nanoparticles of layered structural units made up of one or two tetrahedral silica sheets around an octahedral aluminum sheet. The surface of clay is accessible for anchoring functional molecules. However, they have a very limited adsorption capacity for the removal of heavy metals from aqueous solution. For the purpose of enhancing their adsorption capacity and structural properties, the PANI polymer was incorporated into raw clay in order to develop nanocomposite materials that combine the exceptional properties of each matrix. Montmorillonite (MMT) clay is the most extensively studied filler for polymer nanocomposites; it is a natural, abundant, and inexpensive mineral that has a unique layered structure, large specific surface area, and chemical and mechanical stability, as well as a high cation exchange capacity. Moreover, it is a highly hydrophobic clay, so the presence of MMT clay in a composite improves its hydrophobicity. In this regard, Chen et al. [89] synthesized a flak-like PANI/montmorillonite nanocomposite via in situ chemical polymerization of modified pristine MMT with poly(2-acrylamido-2-methylpropanesulfonic acid), HCl, APS, and aniline monomer. The effectiveness of adsorption by PANI/MMT was evaluated based on $\mathrm{Cr}(\mathrm{VI})$ adsorption. The MMT/PANI ratio of the nanocomposite affects its morphology. An MMT/PANI ratio of 0.25 was found to have the maximum removal efficiency, due to the uniform flake-like structure and rough surface that afford active sites for adsorption. A maximum adsorption capacity of $167.5 \mathrm{mg} / \mathrm{g}$ was obtained at $\mathrm{pH} 2$. Furthermore, the composite showed good adsorption even after four consecutive adsorption/desorption cycles. In another work, a bioconducting starch/montmorillonite/polyaniline nanocomposite was prepared by Olad et al. [90] and employed as a biocompatible, biodegradable, and efficient adsorbent for the removal of $\mathrm{Cr}(\mathrm{VI})$ from aqueous solution. The as-synthesized nanocomposite exhibited a semicrystalline structure with an average particle size between 70 and $90 \mathrm{~nm}$. The maximum adsorption capacity was calculated as $208.33 \mathrm{mg} / \mathrm{g}$ within $15 \mathrm{~min}$. In addition, the as-synthesized nanocomposite was reused for three consecutive cycles.

Ali et al. [91] synthesized two nanocomposites-functional phytic-acid-doped polyaniline (P-PANI), and phytic-acid-doped polyaniline/montmorillonite (P-PANI@ MMT)—by varying the amount of MMT via radical polymerization for the removal of $\mathrm{Cu}$ (II) from aqueous solutions. Phytic acid interacts with amine and imine groups in the PANI matrix; thus, it represents an opportunity for the removal of free metal ions from aqueous media. The authors found that coating the MMT's surface with the P-PANI causes compressive stress on the layers of the MMT; as a result, the d-spacing is decreased, despite the presence of functional groups anchored onto the MMT surface enhancing the capacity for adsorption of $\mathrm{Cu}(\mathrm{II})$. The maximum adsorption capacities for P-PANI and P-PANI@Mt were 66.36 and $87.72 \mathrm{mg} / \mathrm{g}$, respectively, at pH 5 within $10 \mathrm{~min}$. However, the adsorption capacity decreased when increasing the amount of MMT in the composite, which is explained by the tendency of clay particles to aggregate in the PANI matrix and, therefore, hinder the availability of active sites. In a study conducted by Piri et al. [92], a polyaniline/clay nanocomposite was fabricated and tested for the removal of $\mathrm{Pb}$ (II) from aqueous solution. The surface characterization of the PANI/clay nanocomposite showed that the clay layers were flaked in the nanocomposite. Therefore, it was revealed that PANI was introduced in the layers of the clay, resulting in intercalated layered silicate PANI particles. Batch adsorption studies showed that the nanocomposite exhibited a maximum adsorption capacity of $70.4 \mathrm{mg} / \mathrm{g}$ at $\mathrm{pH}$, achieved in $25 \mathrm{~min}$. 
Another category of nanoclays is layered double hydroxides (LDHs). LDHs are unique among layered compounds, because they have positively charged host layers and counteranions in the interlayer. Due to their excellent exchangeability, LDHs can work as precursors to introduce other species to fabricate nanocomposite materials, revealing important applications in adsorption. Zhu et al. [93] reported the synthesis of a Mg/Al $\mathrm{LDH}$ polyaniline nanocomposite. First, $\mathrm{Mg} / \mathrm{Al} \mathrm{LDH}$ was synthesized via a hydrothermal method, followed by in situ oxidative polymerization of aniline monomers on the surface of the LDH. The as-synthesized composite showed a homogenous combination of PANI and the LDH structure, with a rough surface and an average diameter of $200 \mathrm{~nm}$. The composite exhibited a high adsorption capacity for $\mathrm{Cr}(\mathrm{VI})$ ions of $393.7 \mathrm{mg} / \mathrm{g}$ at $\mathrm{pH} 3$ within $90 \mathrm{~min}$. In another work, Dinari and Neamati [94] synthesized citrate-intercalated $\mathrm{Ca} / \mathrm{Fe} \mathrm{LDH}$ modified with aminopropyl trimethoxisilane/polyaniline nanocomposites. The citrate intercalate $\mathrm{Ca} / \mathrm{Fe} \mathrm{LDH}$ was prepared via coprecipitation, and then modified with aminopropyltriethoxysilane followed by polymerization of aniline monomers, and tested for the adsorption of $\mathrm{Pb}(\mathrm{II})$ from aqueous media. The nanocomposite consisted of uniform LDH nanoparticles in the polymer matrix due to the silane coupling agent. According to experimental results, the adsorption capacity was dependent on the solution's $\mathrm{pH}$, and was higher in the sample prepared with a high silane ratio due to the increase in the number of available sites on the surface of $\mathrm{OH}$ and $\mathrm{NH}_{2}$, which are hydrophilic functional groups, and indicate a high tendency to adsorption.

\subsection{Other Nanomaterial-Based PANI Composites}

In addition to the previously cited categories of nanomaterials, other nanomaterials have been cited in the literature as fillers for polyaniline nanocomposites. Hexagonal boron nitride (h-BN) - a two-dimensional material, also known as white graphite, with a similar structure-composed of alternating B and $\mathrm{N}$ atoms, exhibits unique physical and chemical properties such as high specific surface area, numerous structural defects, low density, high chemical durability, oxidation resistance, and excellent thermal stability. However, it also has a distinctive hydrophobicity and poor functional groups on its surface; to overcome these limitations, and depending on its unique abilities, h-BN was used as a supporting nanomaterial. Karthikeyan et al. [95] investigated the removal of $\mathrm{Cr}(\mathrm{VI})$ by a hexagonal boron nitride nanosheet-coated polyaniline, synthesized using a simple in situ chemical oxidation method with various $\mathrm{w} t \%$ of aniline. The prepared nanocomposite, after deposition of PANI onto h-BN, exhibited a distinctive architecture and tubular matrix, exaggerating the surface charge of the prepared material. According to the authors, PANI was heterogeneously substituted and entrenched deeply within the h-BN composite. In addition, it displayed an amorphous and porous nature. The adsorption of $\mathrm{Cr}(\mathrm{VI})$ onto the prepared adsorbent was enhanced when the molar ratio of PANI in the composite increased because of the composite's positive character, due to the compensation of the partial positive effect of PANI on h-BN. The maximum adsorption capacity was $133.44 \mathrm{mg} / \mathrm{g}$ at $\mathrm{pH} 3-5$. The mechanism of adsorption was mainly governed by electrostatic attraction, ion exchange, and complexation combined with reduction, in addition to chelation with possible hydrogen bonding. MoS2 with a graphite-like structure was also used by Qui et al. [96]. The hybrid nanocomposite was fabricated with molybdenum disulfide and acid-doped polyaniline immobilized on porous polyacrylonitrile nanofibers. The uptake process of $\mathrm{Cr}(\mathrm{VI})$ onto the composite was fast, and the equilibrium was achieved in $30 \mathrm{~min}$, with a maximum adsorption capacity of $341.61 \mathrm{mg} / \mathrm{g}$ at $\mathrm{pH} 3$. Ion exchange, electrostatic interactions, and redox reactions were the main mechanisms of $\mathrm{Cr}(\mathrm{VI})$ adsorption. Moreover, the composite was well regenerated, and was reused for six successive cycles without any significant decrease in adsorption capacity.

\section{Regeneration of the Adsorbents}

Regeneration of adsorbents is an important aspect, as it determines their economic feasibility. In general, regeneration is defined as the ability to recover the adsorbate molecules 
accumulated on the surface of the adsorbent in order to regain its initial adsorption capacity and make possible its reuse in another adsorption/desorption cycle. An appropriate adsorbent should exhibit potential regeneration capacity even though its removal efficiency decreases after each regeneration cycle due to the incomplete desorption. The adsorbentadsorbate interaction strength and the adsorbate concentration loaded onto the adsorbent play major roles in the regeneration process. There are three major ways to regenerate adsorbents: thermal regeneration, chemical regeneration, and microbiological regeneration. The choice of an adequate method depends on the type and nature of both the adsorbent and the adsorbate, as well as the cost and processing conditions. For that reason, low-cost, easy-operation, efficient, and ecofriendly regeneration technologies are required to enhance the cost efficacy.

In the case of polyaniline nanocomposite adsorbents, chemical regeneration using acid and base eluents is the most common approach used for regeneration, as can be seen in Table 1. Most of the authors used $\mathrm{NaOH}, \mathrm{HCl}$, or $\mathrm{HNO}_{3}$ solutions for the desorption of absorbed metals from the considered nanocomposite. For example, Lyu et al. [61] evaluated the desorption of $\mathrm{Cr}(\mathrm{VI})$ from polyaniline-coated magnetic nanoparticles using $0.1 \mathrm{M} \mathrm{NaOH}$ solution for $30 \mathrm{~min}$; the authors reported that $80 \%$ of the adsorption capacity was maintained after 10 consecutive cycles. Fan et al. [75] reported the regeneration of a polyaniline/graphene oxide nanocomposite using $0.1 \mathrm{M} \mathrm{HNO}_{3}$ eluent for $24 \mathrm{~h}$; no obvious change in adsorption capacity was observed within seven cycles. In another study, Kumar et al. [82] tried to regenerate a polyaniline/carbon nanotube nanocomposite using water, $0.1 \mathrm{M} \mathrm{HCl}, 0.1 \mathrm{M} \mathrm{NaCl}$, and $0.1 \mathrm{M} \mathrm{NaOH}$. The maximum desorption efficiency was obtained using $0.1 \mathrm{M} \mathrm{NaCl}$ and $0.1 \mathrm{M} \mathrm{NaOH}$. It can be concluded from these studies that the regeneration of polyaniline nanocomposite adsorbents is a simple and feasible process.

Table 1. Summary of various desorbing agents for the regeneration of PANI nanocomposite adsorbents.

\begin{tabular}{|c|c|c|c|c|c|c|}
\hline Composite & Adsorbate & Desorbing Agent & $\begin{array}{l}\text { Number of } \\
\text { Cycles }\end{array}$ & Desorption (\%) & $\begin{array}{l}\text { Removal } \\
\text { Efficiency (\%) }\end{array}$ & Ref. \\
\hline Xanthan gum/ZnO/PANI & $\mathrm{Cr}(\mathrm{VI})$ & $0.2 \mathrm{M} \mathrm{NaOH}$ & 5 & 46 & 51.67 & [48] \\
\hline $\mathrm{ThO}_{2} / \mathrm{PANI}$ & $\mathrm{Cr}(\mathrm{VI})$ & $1 \mathrm{M} \mathrm{NaOH}$ & 5 & - & 85 & [52] \\
\hline $\mathrm{Fe}_{3} \mathrm{O}_{4} / \mathrm{PANI}$ & $\mathrm{Cr}(\mathrm{VI})$ & $\begin{array}{l}1 \mathrm{M} \\
\mathrm{HCl} / \text { sonication }\end{array}$ & - & - & 100 & [56] \\
\hline $\mathrm{Fe}_{3} \mathrm{O}_{4} / \mathrm{PANI}$ & $\mathrm{Cr}(\mathrm{VI})$ & $0.5 \mathrm{M} \mathrm{NaOH}$ & 5 & 90 & - & [57] \\
\hline $\mathrm{yFe}_{3} \mathrm{O}_{4} / \mathrm{PANI}$ & $\mathrm{Cu}(\mathrm{II})$ & $0.1 \mathrm{M} \mathrm{HCl}$ & 4 & 50 & 98 & [58] \\
\hline $\mathrm{yFe}_{3} \mathrm{O}_{4} / \mathrm{PANI}$ & $\mathrm{Cr}(\mathrm{VI})$ & $0.1 \mathrm{M} \mathrm{NaOH}$ & 4 & 40 & 80 & [58] \\
\hline $\mathrm{CL}-\mathrm{PANI} / \mathrm{Fe}_{3} \mathrm{O}_{4}$ & $\mathrm{Cr}(\mathrm{VI})$ & $0.1 \mathrm{M} \mathrm{NaOH}$ & 10 & - & 80 & [61] \\
\hline Magnetic $\mathrm{SiO}_{2} /$ PANI & $\mathrm{Cr}(\mathrm{VI})$ & $0.01 \mathrm{M} \mathrm{NaOH}$ & 5 & - & 66 & [66] \\
\hline $\mathrm{Fe}_{3} \mathrm{O}_{4} @$ PANI-AmAzoTCA[4] & $\begin{array}{l}\mathrm{Cu} \\
\mathrm{Cd} \\
\mathrm{Co} \\
\mathrm{Cr}(\mathrm{III})\end{array}$ & $\begin{array}{l}0.1 \mathrm{M} \mathrm{HCl} \\
0.1 \mathrm{M} \mathrm{HCl} \\
0.1 \mathrm{M} \mathrm{HCl} \\
0.1 \mathrm{M} \mathrm{HCl}\end{array}$ & $\begin{array}{l}3 \\
3 \\
3 \\
3\end{array}$ & $\begin{array}{l}- \\
- \\
-\end{array}$ & $\begin{array}{l}95.9 \\
93.3 \\
92 \\
94\end{array}$ & [67] \\
\hline $\mathrm{PS} / \mathrm{Fe}_{3} \mathrm{O}_{4} @ \mathrm{PANI}$ & $\mathrm{Cu}(\mathrm{II})$ & $0.1 \mathrm{M} \mathrm{HCl}$ & 8 & - & 83 & [68] \\
\hline GO/PANI & $\operatorname{Hg}(\mathrm{II})$ & $0.1 \mathrm{M} \mathrm{HNO}_{3}$ & 7 & - & 70 & [75] \\
\hline GO/PANI & $\mathrm{Zn}$ & $\mathrm{pH}=7$ & 4 & - & 50 & [77] \\
\hline $\mathrm{Fe}_{3} \mathrm{O}_{4} / \mathrm{GO} / \mathrm{PANI}$ & $\mathrm{Cu}(\mathrm{II})$ & $\mathrm{pH}=5.8$ & 6 & - & 90 & [79] \\
\hline rGO/PANI & $\operatorname{Hg}(\mathrm{II})$ & $\begin{array}{l}\mathrm{pH}=1 \\
\mathrm{pH}=13\end{array}$ & - & $\begin{array}{l}50.4 \\
73.4\end{array}$ & $\begin{array}{l}- \\
-\end{array}$ & [80] \\
\hline DP/MWCNT/PANI & $\mathrm{Cr}(\mathrm{VI})$ & $\begin{array}{l}0.1 \mathrm{M} \mathrm{NaCl} \\
0.1 \mathrm{M} \mathrm{NaOH} \\
1 \mathrm{M} \mathrm{NaOH} \\
1 \mathrm{M} \mathrm{NaOH}\end{array}$ & $\begin{array}{l}- \\
- \\
- \\
-\end{array}$ & $\begin{array}{l}2.9 \\
10.5 \\
20.77 \\
24\end{array}$ & $\begin{array}{l}- \\
- \\
- \\
-\end{array}$ & [82] \\
\hline pTSA-Pani@CNT & $\mathrm{Cr}(\mathrm{VI})$ & $\begin{array}{l}0.1 \mathrm{M} \mathrm{NaOH} \\
0.1 \mathrm{M} \mathrm{HCl} \\
\text { Acetone }\end{array}$ & 3 & - & $\simeq 98$ & [83] \\
\hline h-BN/PANI & $\mathrm{Cr}(\mathrm{VI})$ & $0.1 \mathrm{M} \mathrm{NaOH}$ & 5 & - & - & [95] \\
\hline $\mathrm{MoS}_{2} / \mathrm{PANI} / \mathrm{PAN}$ & $\mathrm{Cr}(\mathrm{VI})$ & $0.5 \mathrm{M} \mathrm{NaOH}$ & 6 & - & $\simeq 88$ & [96] \\
\hline
\end{tabular}




\section{Conclusions and Perspectives}

This review article presents different polyaniline-nanocomposite-based nanomaterials for the removal of heavy metals from aqueous solution, using the adsorption process as one of the most simple, effective, and economical methods for water treatment. From the large number of published studies reviewed here, it can be observed that the preparation methods and synthesis conditions such as $\mathrm{pH}$, temperature, and the presence of dopants are of great importance, as they influence the morphology and adsorption properties of the resulting nanocomposite. Hexavalent chromium was the most studied heavy metal using PANI nanocomposite adsorbents, due to the fact that it is widely used in numerous industries, poses a threat to the environment, and can cause harmful diseases. Polyaniline in the prepared nanocomposites was found in emeraldine form. The use of dopants and surfactants enhanced the adsorption capacity of the nanocomposites. The $\mathrm{CoFe}_{2} \mathrm{O}_{3} / \mathrm{PANI}$ nanocomposite was found to be the most effective nanocomposite for $\mathrm{Cr}(\mathrm{VI})$ removal compared with other metal oxide/PANI nanocomposites. In addition, coating spinel with PANI inhibited leaching. Moreover, PANI nanocomposites exhibited enhanced thermal stability compared to PANI alone. A GO/PANI nanocomposite exhibited the highest adsorption capacity. Based on thermodynamic studies, the adsorption of heavy metals on nanocomposites was found to be mostly endothermic. In addition, the mechanism and kinetics of adsorption of heavy metals on various PANI nanocomposite adsorbents depend on the chemical nature of the materials and various physicochemical experimental conditions, such as $\mathrm{pH}$, adsorbent dosage, initial metal ion concentration, and the presence of coexisting ions. Therefore, these factors are to be taken into account when evaluating the adsorption capacity of different adsorbents. This review article also reveals that the Langmuir and Freundlich adsorption isotherm models are usually used to evaluate the adsorption capacity of various nanocomposites. The kinetic data of adsorption of heavy metals usually follow the pseudo-second-order kinetic model and Freundlich isotherm. Furthermore, the nanocomposites displayed good recyclability, which is a crucial feature in the adsorption process.

Despite the great number of research articles published in the field of polyaniline nanocomposite adsorbents for the removal of heavy metals, the application of these composites for large-scale water treatment and desalination did not attain their optimal performance. The future perspectives to achieve optimal performance of the adsorbents are as follows:

- Searching for more low-cost and easily available nanomaterials to combine with polyaniline in order to decrease the production costs and sustain the adsorbent-based market;

- Functionalizing nanocomposites by increasing the number of functional groups that are able to enhance the adsorption efficiency and improve the selectivity of the adsorbents;

- Conducting large-scale studies and evaluating the operational costs for real wastewater treatment.

Author Contributions: Conceptualization, H.H., W.B. and N.B.; methodology, H.H. and A.S.; writing - original draft, H.H. and A.S.; writing - review and editing, W.B. and N.B.; supervision, M.A. and N.B. All authors have read and agreed to the published version of the manuscript.

Funding: This research received no external funding.

Conflicts of Interest: The authors declare no conflict of interest.

\section{References}

1. Hong, Y.S.; Song, K.H.; Chung, J.Y. Health effects of chronic arsenic exposure. J. Prev. Med. Public Health 2014, 47, $245-252$. [CrossRef]

2. Adams, J.Y.U.; Keen, C.L. Copper, oxidative stress and human health. Mol. Asp. Med. 2005, 26, 268-298. [CrossRef]

3. Kumari, S.; Jamwal, A.R.; Mishra, N.; Singh, D.K. Recent developments in environmental mercury bioremediation and its toxicity: A review. Environ. Nanotechnol. Monit. Manag. 2020, 13, 100283. [CrossRef]

4. Brochin, R.; Leone, S.; Philips, D.; Shepard, N.; Zisa, D.; Angerio, A. The Cellular Effect of Lead Poisoning and Its Clinical Picture. Georg. Undergrad. J. Health Sci. 2008, 5, 1-19. 
5. Schwarzenbach, R.P.; Egli, T.; Hofstetter, T.B.; Gunten, U.V.; Wehrli, B. Global Water Pollution and Human Health. Annu. Rev. Environ. Resour. 2010, 35, 100809-125342. [CrossRef]

6. Wang, J.; Zhang, Q.; Shao, X.; Ma, J.; Tian, G. Properties of magnetic carbon nanomaterials and application in removal organic dyes. Chemosphere 2018, 207, 377-384. [CrossRef] [PubMed]

7. Machrouhi, A.; Farnane, M.; Elhalil, A.; Abdennouri, M.; Tounsadi, H.; Barka, N. Heavy metals biosorption by Thapsia transtagana stems powder: Kinetics, equilibrium and thermodynamics. Moroc. J. Chem. 2019, 7, 98-110.

8. Farnane, M.; Machrouhi, A.; Khnifira, M.; Barour, M.; Elmoubaraki, R.; Abdennouri, M.; Tounsadi, H.; Qoursal, S.; Barka, N. Facile nitric acid activation of carob seeds for efficient recovery of heavy metals from water. Desalin. Water Treat. 2020, 204, 174-188. [CrossRef]

9. Seid, A.; Chouder, D.; Maouche, N.; Bakas, I.; Barka, N. Removal of Cd(II) and Co(II) ions from aqueous solutions by polypyrrole particles: Kinetics, equilibrium and thermodynamics. J. Taiwan Inst. Chem. Eng. 2014, 45, 2969-2974. [CrossRef]

10. Hayati, B.; Maleki, A.; Najafi, F.; Gharibi, F.; McKay, G.; Gupta, V.K.; Puttaiah, S.H.; Marzban, N. Heavy metal adsorption using PAMAM/CNT nanocomposite from aqueous solution in batch and continuous fixed bed systems. Chem. Eng. J. 2018, 346, 258-270. [CrossRef]

11. Repo, E.; Warchol, J.K.; Bhatnagar, A.; Sillanpää, M. Heavy metals adsorption by novel EDTA-modified chitosan-silica hybrid materials. J. Colloid Interface Sci. 2011, 358, 261-267. [CrossRef]

12. Da'na, E. Adsorption of heavy metals on functionalized-mesoporous silica: A review. Microporous Mesoporous Mater. 2017, 247, 145-157. [CrossRef]

13. Barka, N.; Ouzaouit, K.; Abdennouri, M.; El Makhfouk, M.; Qourzal, S.; Assabbane, A.; Ait Ichou, Y.; Nounah, A. Kinetics and equilibrium of cadmium removal from aqueous solutions by sorption onto synthesized hydroxyapatite. Desalin. Water Treat. 2012, 43, 8-16. [CrossRef]

14. Tounsadi, H.; Khalidi, A.; Farnane, M.; Abdennouri, M.; Barka, N. Experimental design for the optimization of preparation conditions of highly efficient activated carbon from Glebionis Coronaria L. and heavy metals removal ability. Process Saf. Environ. Prot. 2016, 102, 710-723. [CrossRef]

15. Verma, M.; Tyagi, I.; Chandra, R.; Gupta, V.K. Adsorptive removal of $\mathrm{Pb}$ (II) ions from aqueous solution using CuO nanoparticles synthesized by sputtering method. J. Mol. Liq. 2016, 225, 936-944. [CrossRef]

16. Van der Merwe, D.; Pickrell, J.A. Toxicity of Nanomaterials. In Veterinary Toxicology, 3rd ed.; Gupta, R.C., Ed.; Academic Press: Cambridge, MA, USA, 2018; pp. 319-326.

17. Roy, R.; Roy, R.A.; Roy, D.M. Alternative perspectives on "Quasi-crystallinity": Non-uniformity and nanocomposites. Mater. Lett. 1986, 4, 323-328. [CrossRef]

18. Venkatachalam, S. Ultraviolet and visible spectroscopy studies of nanofillers and their polymer nanocomposites. In Spectroscopy of Polymer Nanocomposites; Thomas, S., Rouxel, D., Ponnamma, D., Eds.; William Andrew Publishing: Norwich, NY, USA, 2016; pp. 130-157.

19. Zare, E.; Motahari, A.; Sillanpää, M. Nanoadsorbents based on conducting polymer nanocomposites with main focus on polyaniline and its derivatives for removal of heavy metal ions/dyes: A review. Environ. Res. 2018, 162, 173-195. [CrossRef]

20. Bhadra, S.; Khastgir, D.; Singha, N.K.; Lee, J.H. Progress in preparation, processing and applications of polyaniline. Prog. Polym. Sci. 2009, 34, 783-810. [CrossRef]

21. Sahayam, A.C. Determination of $\mathrm{Cd}, \mathrm{Cu}, \mathrm{Pb}$ and $\mathrm{Sb}$ in environmental samples by ICP-AES using polyaniline for separation. Fresenius J. Anal. Chem. 1998, 362, 285-288. [CrossRef]

22. Wu, H.; Wang, Q.; Fei, G.T.; Xu, S.H.; Guo, X.; Zhang, L.D. Preparation of Hollow Polyaniline Micro/Nanospheres and Their Removal Capacity of Cr (VI) from Wastewater. Nanoscale Res. Lett. 2018, 13, 401. [CrossRef]

23. Li, T.; Qin, Z.; Liang, B.; Tian, F.; Zhao, J.; Liu, N.; Zhu, M. Morphology-dependent capacitive properties of three nanostructured polyanilines through interfacial polymerization in various acidic media. Electrochim. Acta 2015, 177, 343-351. [CrossRef]

24. Shen, Y.; Qin, Z.; Li, T.; Zeng, F.; Chen, Y.; Liu, N. Boosting the supercapacitor performance of polyaniline nanofibers through sulfonic acid assisted oligomer assembly during seeding polymerization process. Electrochim. Acta 2020, 356, 136841. [CrossRef]

25. Rahman, S.U.; Röse, P.; Shah, A.U.H.A.; Krewer, U.; Bilal, S. An amazingly simple, fast and green synthesis route to polyaniline nanofibers for efficient energy storage. Polymers 2020, 12, 2212. [CrossRef] [PubMed]

26. Daka, J.J.; Munyati, O.M.; Nyirenda, J. Iron chlorophyll-a as biomimic catalyst for the green synthesis of polyaniline nanostructures: Evaluation, characterization and optimization. Sustain. Chem. Pharm. 2019, 15, 100194. [CrossRef]

27. Wang, J.; Deng, B.; Chen, H.; Wang, X.; Zheng, J. Removal of Aqueous Hg(II) by Polyaniline: Sorption Characteristics and Mechanisms. Environ. Sci. Technol. 2009, 43, 5223-5228. [CrossRef]

28. Lyu, W.; Yu, M.; Fen, J.; Yan, W. Facile synthesis of coral-like hierarchical polyaniline micro/nanostructures with enhanced supercapacitance and adsorption performance. Polymer 2019, 162, 130-138. [CrossRef]

29. Song, E.; Choi, J.W. Self-calibration of a polyaniline nanowire-based chemiresistive pH sensor. Microelectron. Eng. 2014, 116, 26-32. [CrossRef]

30. Noby, H.; El-Shazly, A.H.; Elkady, M.F.; Ohshima, M. Strong acid doping for the preparation of conductive polyaniline nanoflowers, nanotubes, and nanofibers. Polymer 2019, 182, 121848. [CrossRef]

31. Akbar, A.; Das, M.; Sarkar, D. Room temperature ammonia sensing by CdS nanoparticle decorated polyaniline (PANI) nanorods. Sens. Actuators A. 2020, 310, 112071. [CrossRef] 
32. Lei, Y.; Zhou, J.; Yao, Z.; Li, L. Self-assembly of porous polyaniline microspheres via template-free interfacial method for high-performance electromagnetic absorption property. Mater. Lett. 2020, 265, 127389. [CrossRef]

33. Noby, H.; El-Shazly, A.A.; Elkady, M.F.; Ohshima, M. Novel preparation of self-assembled HCl-doped polyaniline nanotubes using compressed $\mathrm{CO}_{2}$-assisted polymerization. Polymer 2018, 156, 71-75. [CrossRef]

34. Sun, L.; Zhan, L.; Shi, Y.; Chu, L.; Ge, G.; He, Z. Microemulsion synthesis and electromagnetic wave absorption properties of monodispersed Fe3O4/polyaniline core-shell nanocomposites. Synth. Met. 2014, 187, 102-107. [CrossRef]

35. Guo, H.; Zhu, H.; Lin, H.; Zhang, J. Synthesis of polyaniline/multi-walled carbon nanotube nanocomposites in water/oil microemulsion. Mater. Lett. 2008, 62, 3919-3921. [CrossRef]

36. Karim, M.R.; Woo, H.W.; Cheong, I.W.; Park, S.M.; Oh, W.; Yeum, J.H. Conducting Polyaniline-Titanium Dioxide Nanocomposites Prepared by Inverted Emulsion Polymerization. Polym. Polym. Compos. 2008, 31, 83-88. [CrossRef]

37. Regueira, R.; Suckeveriene, R.Y.; Brook, I.; Mechrez, G.; Tchoudakov, R.; Narkis, M. Investigation of the Electro-Mechanical Behavior of Hybrid Polyaniline/Graphene Nanocomposites Fabricated by Dynamic Interfacial Inverse Emulsion Polymerization. Sci. Res. Publ. 2015, 4, 7-19. [CrossRef]

38. Wang, N.; Chen, J.; Wang, J.; Feng, J.; Yan, W. Removal of methylene blue by Polyaniline/TiO 2 hydrate: Adsorption kinetic, isotherm and mechanism studies. Powder Technol. 2019, 347, 93-102. [CrossRef]

39. Pina, C.D.; Rossi, M.; Ferretti, A.M.; Ponti, A.; Lo Faro, M.; Falletta, E. One-pot synthesis of polyaniline/ $/ \mathrm{Fe}_{3} \mathrm{O}_{4}$ nanocomposites with magnetic and conductive behaviour. Catalytic effect of $\mathrm{Fe}_{3} \mathrm{O}_{4}$ nanoparticles. Synth. Met. 2012, 162, 2250-2258. [CrossRef]

40. Zong, P.; Cheng, Y.; Wang, S.; Wang, L. Simultaneous removal of Cd(II) and phenol pollutions through magnetic graphene oxide nanocomposites coated polyaniline using low temperature plasma technique. Int. J. Hydrog. Energy 2020, 45, 20106-20119. [CrossRef]

41. Yoshimoto, S.; Ohashi, F.; Ohnishi, Y.; Nonami, T. Synthesis of polyaniline-montmorillonite nanocomposites by the mechanochemical intercalation method. Synth. Met. 2004, 145, 265-270. [CrossRef]

42. Rajakumar, K.; Kirupha, S.D.; Sivanesan, S.; Sai, R.L. Effective removal of heavy metal ions using $\mathrm{Mn}_{2} \mathrm{O}_{3}$ doped polyaniline nanocomposite. J. Nanosci. Nanotechnol. 2014, 14, 2937-2946. [CrossRef]

43. Khalili, R.; Eisazadeh, H. Preparation and Characterization of Polyaniline $/ \mathrm{Sb}_{2} \mathrm{O}_{3}$ Nanocomposite and its Application for Removal of $\mathrm{Pb}(\mathrm{II})$ from Aqueous Media. Int. J. Eng. 2013, 27, 239-246.

44. Piri, S.; Piri, F.; Rajabi, B.; Ebrahimi, S.; Zamani, A.; Yaftian, M.R. In situ One-pot Electrochemical Synthesis of Aluminum Oxide/polyaniline Nanocomposite; Characterization and Its Adsorption Properties towards Some Heavy Metal Ions. J. Chin. Chem. Soc. 2015, 62, 1045-1052. [CrossRef]

45. Nath, B.K.; Chaliha, C.; Kalita, E.; Kalita, M.C. Synthesis and characterization of ZnO:CeO ${ }_{2}$ :nanocellulose:PANI bionanocomposite. A bimodal agent for arsenic adsorption and antibacterial action. Carbohydr. Polym. 2016, 148, 397-405. [CrossRef] [PubMed]

46. Moosavian, M.A.; Moazezi, N. Removal of cadmium and zinc ions from industrial wastewater using nanocomposites of PANI/ZnO and PANI/CoHCF: A comparative study. Desalin. Water Treat. 2015, 57, 20817-20836. [CrossRef]

47. Ahmad, R. Polyaniline/ZnO Nanocomposite: A Novel Adsorbent for the Removal of Cr(VI) from Aqueous Solution. In Advances in Composite Materials Development; Lucan, D., Ed.; IntechOpen: London, UK, 2019.

48. Ahmad, R.; Hasan, I. Efficient Remediation of an Aquatic Environment Contaminated by Cr (VI) and 2,4-Dinitrophenol by XG g-Polyaniline@ZnO Nanocomposite. J. Chem. Eng. Data 2017, 62, 1594-1607. [CrossRef]

49. Brungesh, K.V.; Nagabhushana, B.M.; Harish, M.N.K.; Hari Krishna, R. An Efficient Removal of Toxic Cr(VI) from Aqueous Solution by $\mathrm{MnO}_{2}$ Coated Polyaniline Nanofibers: Kinetic and Thermodynamic Study. J. Environ. Anal. Toxicol. $2017,7,442$.

50. Chen, J.; Wang, N.; Liu, Y.; Zhu, J.; Feng, J.; Yan, W. Synergetic effect in a self-doping polyaniline/ TiO 2 composite for selective adsorption of heavy metal ions. Synth. Met. 2018, 245, 32-41. [CrossRef]

51. Khong, C.H.; Teh, G.B.; Phang, S.W. Effect of Titanium Dioxide and Carbon Nanotubes on Polyaniline Nanocomposites for Heavy Metals Removal. Macromol. Symp. 2018, 382, 1800087. [CrossRef]

52. Sahu, S.; Sahu, U.K.; Patel, R. Modified Thorium Oxide Polyaniline Core-Shell Nanocomposite and Its Application for the Efficient Removal of Cr(VI). J. Chem. Eng. Data 2019, 64, 1294-1304. [CrossRef]

53. Bhaumik, M.; Gupta, V.K.; Maity, A. Synergetic enhancement of $\mathrm{Cr}(\mathrm{VI})$ removal from aqueous solutions using polyaniline@Ni(OH) 2 nanocomposites adsorbent. J. Environ. Chem. Eng. 2018, 6, 2514-2527. [CrossRef]

54. Wei, X.; Liu, Q.; Zhang, H.; Liu, J.; Chen, R.; Li, R.; Li, Z.; Liu, P.; Wang, J. Rapid and efficient uranium(VI) capture by phytic acid/polyaniline/FeOOH composites. J. Colloid Interface Sci. 2018, 511, 1-11. [CrossRef]

55. Liu, J.F.; Zhao, Z.S.; Jiang, G.B. Coating $\mathrm{Fe}_{3} \mathrm{O}_{4}$ magnetic nanoparticles with humic acid for high efficient removal of heavy metals in water. Environ. Sci. Technol. 2008, 42, 6949-6954. [CrossRef]

56. Gu, H.; Rapole, S.B.; Sharma, J.; Huang, Y.; Cao, D.; Colorado, H.A.; Luo, Z.; Haldolaarachchige, N.; Young, D.P.; Walters, B.; et al. Magnetic polyaniline nanocomposites toward toxic hexavalent chromium removal. RSC Adv. 2012, 2, 11007-11018. [CrossRef]

57. Han, X.; Gai, L.; Jiang, H.; Zhao, L.; Liu, H.; Zhang, W. Core-shell structured $\mathrm{Fe}_{3} \mathrm{O}_{4} / \mathrm{PANI}$ microspheres and their Cr(VI) ion removal properties. Synth. Met. 2013, 171, 1-6. [CrossRef]

58. Chávez-Guajardo, A.E.; Llamas, J.C.M.; Maqueira, L.; Andrade, C.A.S.; Alves, K.G.B.; Melo, C.P. Efficient removal of Cr(VI) and $\mathrm{Cu}$ (II) ions from aqueous media by use of polypyrrole/maghemite and polyaniline/maghemite magnetic nanocomposites. Chem. Eng. J. 2015, 281, 826-836. [CrossRef] 
59. Ebrahim, S.; Shokry, A.; Ibrahim, H.; Soliman, M. Polyaniline/akaganéite nanocomposite for detoxification of noxious Cr(VI) from aquatic environment. J. Polym. Res. 2016, 23, 79. [CrossRef]

60. Sadeghi, M.M.; Rad, A.S.; Ardjmand, M.; Mirabi, A. Preparation of magnetic nanocomposite based on polyaniline $/ \mathrm{Fe}_{3} \mathrm{O}_{4}$ towards removal of lead (II) ions from real samples. Synth. Met. 2018, 245, 1-9. [CrossRef]

61. Lyu, W.; Wu, J.; Zhang, W.; Liu, Y.; Yu, M.; Zhao, Y.; Feng, J.; Yan, W. Easy separated 3D hierarchical coral-like magnetic polyaniline adsorbent with enhanced performance in adsorption and reduction of $\mathrm{Cr}(\mathrm{VI})$ and immobilization of $\mathrm{Cr}(\mathrm{III})$. Chem. Eng. J. 2019, 363, 107-119. [CrossRef]

62. Agrawal, S.; Singh, N.B. Removal of toxic hexavalent chromium from aqueous solution by nickel ferrite-polyaniline nanocomposite. Desalin. Water Treat. 2015, 57, 17757-17766. [CrossRef]

63. Bhaumik, M.; Choi, H.J.; Mccrindle, R.I.; Maity, A. Composite nanofibers prepared from metallic iron nanoparticles and polyaniline: High performance for water treatment applications. J. Colloid Interface Sci. 2014, 425, 75-82. [CrossRef] [PubMed]

64. Singh, N.B.; Rachna, K. Copper ferrite-Polyaniline nanocomposite and its application for Cr (VI) ion removal from aqueous solution. Environ. Nanotechnol. Monit. Manag. 2019, 14, 100301.

65. Yang, G.; Tang, L.; Cai, Y.; Zeng, G.; Guo, P.; Chen, G.; Zhou, Y.; Tang, J.; Chen, J.; Xiong, W. Effective removal of Cr(VI) through adsorption and reduction by magnetic mesoporous carbon incorporated with polyaniline. RSC Adv. 2014, 4, 58362-58371. [CrossRef]

66. Tang, L.; Fang, Y.; Pang, Y.; Zeng, G.; Wang, J.; Zhou, Y.; Deng, Y.; Yang, G.; Cai, Y.; Chen, J. Synergistic adsorption and reduction of hexavalent chromium using highly uniform polyaniline-magnetic mesoporous silica composite. Chem. Eng. J. 2014, 254, 302-312. [CrossRef]

67. Norouzian, R.S.; Lakouraj, M.M. Preparation and heavy metal ion adsorption behavior of novel supermagnetic nanocomposite based on thiacalix[4]arene and polyaniline: Conductivity, isotherm and kinetic study. Adv. Polym. Technol. 2015, 36, 107-119. [CrossRef]

68. Li, Y.; Qiu, J.; Ye, S.; Wang, L.; Yang, C.; Sun, P.; Wang, C. Facile fabrication of $\mathrm{PS} / \mathrm{Fe}_{3} \mathrm{O}_{4} @ \mathrm{PANi}$ nanocomposite particles and their application for the effective removal of $\mathrm{Cu}^{2+}$. N. J. Chem. 2017, 41, 14137-14144. [CrossRef]

69. Zhang, J.; Han, J.; Wang, M.; Guo, R. $\mathrm{Fe}_{3} \mathrm{O}_{4}$ /PANI/ $\mathrm{MnO}_{2}$ Core-Shell Hybrids as Advanced Adsorbents for Heavy Metal Ions. J. Mater. Chem. A 2017, 5, 4058-4406. [CrossRef]

70. Lei, C.; Wang, C.; Chen, W.; He, M.; Huang, B. Polyaniline@magnetic chitosan nanomaterials for highly efficient simultaneous adsorption and in-situ chemical reduction of hexavalent chromium: Removal efficacy and mechanisms. Sci. Total Environ. 2020, 733, 139316. [CrossRef]

71. Kumar, R.; Barakat, M.A.; Taleb, M.A.; Seliem, M.K. A recyclable multifunctional graphene oxide $/ \mathrm{SiO}_{2} @$ polyaniline microspheres composite for $\mathrm{Cu}(\mathrm{II})$ and $\mathrm{Cr}(\mathrm{VI})$ decontamination from wastewater. J. Clean Prod. 2020, 268, 122290. [CrossRef]

72. Taleb, M.A.; Kumar, R.; Al-Rashdi, A.A.; Seliem, M.K.; Barakat, M.A. Fabrication of $\mathrm{SiO}_{2} / \mathrm{CuFe}_{2} \mathrm{O}_{4} /$ polyaniline composite: A highly efficient adsorbent for heavy metals removal from aquatic environment. Arab. J. Chem. 2020, 13, 7533-7543. [CrossRef]

73. Vargas, L.R.; Poli, A.K.; Dutra, R.C.L.; Souza, C.B.; Baldan, M.R.; Gonçalves, E.S. Formation of composite polyaniline and graphene oxide by physical mixture method. J. Aerosp. Technol. Manag. 2017, 9, 29-38. [CrossRef]

74. Zhang, S.; Zeng, M.; Xu, W.; Li, J.; Li, J.; Xu, J.; Wang, X. Polyaniline nanorods dotted on graphene oxide nanosheets as a novel super adsorbent for Cr(VI). Dalton Trans. 2013, 42, 7854-7858. [CrossRef]

75. Fan, Q.; Yang, Y.; Hao, Y.; Zhao, X.; Feng, Y. Preparation of three-dimensional PANI/GO for the separation of Hg(II) from aqueous solution. J. Mol. Liq. 2015, 212, 557-562. [CrossRef]

76. Harijan, D.K.L.; Chandra, V. Polyaniline functionalized graphene sheets for treatment of toxic hexavalent chromium. J. Environ. Chem. Eng. 2016, 4, 3006-3012. [CrossRef]

77. Ramezanzadeh, M.; Asghari, M.; Ramezanzadeh, B.; Bahlakeh, G. Fabrication of an efficient system for Zn ions removal from industrial wastewater based on graphene oxide nanosheets decorated with highly crystalline polyaniline nanofibers (GO- PANI): Experimental and ab initio quantum mechanics approaches. Chem. Eng. J. 2017, 337, 385-397. [CrossRef]

78. Yang, J.; Wu, J.X.; Lü, Q.F.; Lin, T.T. Facile preparation of lignosulfonate-graphene oxide-polyaniline ternary nanocomposite as an effective adsorbent for $\mathrm{Pb}(\mathrm{II})$ ions. ACS Sustain. Chem. Eng. 2014, 2, 1203-1211. [CrossRef]

79. Liu, Y.; Chen, L.; Li, Y.; Wang, P.; Dong, Y. Synthesis of magnetic polyaniline/graphene oxide composites and their application in the efficient removal of $\mathrm{Cu}$ (II) from aqueous solutions. J. Environ. Chem. Eng. 2015, 4, 825-834. [CrossRef]

80. Li, R.; Liu, L.; Yang, F. Polyaniline/reduced graphene oxide $/ \mathrm{Fe}_{3} \mathrm{O}_{4}$ nano-composite for aqueous $\mathrm{Hg}$ (II) removal. Water Sci. Technol. 2015, 72, 2062-2070. [CrossRef]

81. Shao, D.; Chen, C.; Wang, X. Application of polyaniline and multiwalled carbon nanotube magnetic composites for removal of $\mathrm{Pb}(\mathrm{II})$. Chem. Eng. J. 2011, 185-186, 144-150. [CrossRef]

82. Kumar, R.; Ansari, M.O.; Barakat, M.A. DBSA doped polyaniline/multi-walled carbon nanotubes composite for high efficiency removal of $\mathrm{Cr}(\mathrm{VI})$ from aqueous solution. Chem. Eng. J. 2013, 228, 748-755. [CrossRef]

83. Kumar, R.; Ansari, M.O.; Alshahrie, A.; Darwesh, R.; Parveen, N.; Yadav, S.K.; Barakat, M.A.; Cho, M.H. Adsorption modeling and mechanistic insight of hazardous chromium on para toluene sulfonic acid immobilized-polyaniline@CNTs nanocomposites. J. Saudi Chem. Soc. 2018, 23, 188-197. [CrossRef] 
84. Ansari, M.O.; Kumar, R.; Ansari, S.A.; Ansari, S.P.; Barakat, M.A.; Alshahrie, A.; Cho, M.H. Anion selective pTSA doped polyaniline@graphene oxide-multiwalled carbon nanotube composites for $\mathrm{Cr}(\mathrm{VI})$ and Congo red adsorption. J. Colloid Interface Sci. 2017, 496, 407-415. [CrossRef] [PubMed]

85. Karthik, R.; Meenakshi, S. Removal of hexavalent chromium ions using polyaniline/silica gel composite. J. Water Process Eng. 2014, 1, 37-45. [CrossRef]

86. Javadian, H.; Vahedian, P.; Toosi, M. Adsorption characteristics of Ni(II) from aqueous solution and industrial wastewater onto Polyaniline/HMS nanocomposite powder. Appl. Surf. Sci. 2013, 284, 13-22. [CrossRef]

87. Javadian, H.; Sorkhrodi, F.Z.; Koutenaei, B.B.; Naushad, M.; Desoky, G.E.B.E. Experimental investigation on enhancing aqueous cadmium removal via nanostructure composite of modified hexagonal type mesoporous silica with polyaniline/polypyrrole nanoparticles. J. Ind. Eng. Chem. 2014, 20, 3678-3688. [CrossRef]

88. Mahmoud, M.E.; Fekry, N.A.; El-latif, M.M.A. Nanocomposites of nanosilica-immobilized-nanopolyaniline and crosslinked nanopolyaniline for removal of heavy metals. Chem. Eng. J. 2016, 304, 679-691. [CrossRef]

89. Chen, J.; Hong, X.; Zhao, Y.; Xia, Y.; Li, D.; Zhang, Q. Preparation of flake-like polyaniline/montmorillonite nanocomposites and their application for removal of $\mathrm{Cr}(\mathrm{VI})$ ions in aqueous solution. J. Mater. Sci. 2013, 48, 7708-7717. [CrossRef]

90. Olad, A.; Bastanian, M.; Bakht, H.; Hagh, K. Thermodynamic and Kinetic Studies of Removal Process of Hexavalent Chromium Ions from Water by Using Bio conducting Starch-Montmorillonite/Polyaniline Nanocomposite. J. Inorg. Organomet. Polym. Mater. 2019, 29, 1916-1926. [CrossRef]

91. Ali, M.B.; Wang, F.; Boukherroub, R.; Lei, W.; Xia, M. Phytic acid-doped polyaniline nanofibers-clay mineral for efficient adsorption of copper (II) ions. J. Colloid Interface Sci. 2019, 553, 688-698. [PubMed]

92. Piri, S.; Zanjani, Z.A.; Piri, F.; Zamani, A.; Yaftian, M.; Davari, M. Potential of polyaniline modified clay nanocomposite as a selective decontamination adsorbent for $\mathrm{Pb}(\mathrm{II})$ ions from contaminated waters; kinetics and thermodynamic study. J. Environ. Health Sci. Eng. 2016, 14, 20. [CrossRef] [PubMed]

93. Zhu, K.; Gao, Y.; Tan, X.; Chen, C. Polyaniline-Modified Mg/Al Layered Double Hydroxide Composites and Their Application in Efficient Removal of Cr(VI). ACS Sustain. Chem. Eng. 2016, 4, 4361-4369. [CrossRef]

94. Dinari, M.; Neamati, S. Surface modified layered double hydroxide/polyaniline nanocomposites: Synthesis, characterization and $\mathrm{Pb}^{2+}$ removal. Colloids Surf. A Physicochem. Eng. Asp. 2020, 589, 124438. [CrossRef]

95. Karthikeyan, P.; Elanchezhiyan, S.S.D.; Preethi, J.; Meenakshi, S.; Park, C.M. Mechanistic performance of polyaniline-substituted hexagonal boron nitride composite as a highly efficient adsorbent for the removal of phosphate, nitrate, and hexavalent chromium ions from an aqueous environment. Appl. Surf. Sci. 2020, 511, 145543. [CrossRef]

96. Qiu, J.; Liu, F.; Cheng, S.; Zong, L.; Zhu, C.; Ling, C.; Li, A. Recyclable Nanocomposite of Flowerlike MoS $@$ Hybrid Acid-Doped PANI Immobilized on Porous PAN Nanofibers for the Efficient Removal of Cr(VI). ACS Sustain. Chem. Eng. 2017, 6, 447-456. [CrossRef] 